\title{
Standardized stimuli and procedures for investigating the retrieval of lexical and conceptual knowledge for actions
}

\author{
J. A. FIEZ \\ University of Iowa College of Medicine, Iowa City, Iowa \\ and Washington University School of Medicine, St. Louis, Missouri \\ and \\ D. TRANEL \\ University of Iowa College of Medicine, Iowa City, Iowa
}

\begin{abstract}
We have developed a set of naming and recognition tests for evaluating the retrieval of lexical and conceptual knowledge for actions. As a first step, normative information about 280 items was collected for the following variables: (1) the naming responses elicited by each item, (2) the degree to which the image of each item agreed with a target name, (3) the familiarity of each depicted action, and (4) the visual complexity of each item. This information was used to develop administration and scoring procedures for a standardized test of action naming. The effectiveness and reliability of these procedures were evaluated in a second experiment. In a third experiment, five tests were developed to probe the retrieval of conceptual knowledge: (1) independently of the production of a naming response, (2) in response to pictorial and nonpictorial stimuli, (3) in terms of the attributes associated with specific actions, and (4) in terms of similarities and differences between various actions.
\end{abstract}

An important goal of neuroscience is to further our understanding of the psychological and neuroanatomical organization of conceptual knowledge about the world. One paradigm for such investigation involves the study of brain-damaged patients in controlled cognitive experiments. Intriguing dissociations in the ability of braindamaged subjects to retrieve conceptual and lexical (word) information about concrete entities have been found. Some subjects have difficulty retrieving lexical forms (nouns) for various entities, although their retrieval of conceptual knowledge about entities may be intact; furthermore, brain-damaged subjects may lose the capacity to retrieve either conceptual or lexical knowledge related to specific classes of entities (e.g., animals), but not others (e.g., tools). ${ }^{1}$

Curiously, nearly all studies in which the lesion method has been used to investigate knowledge retrieval have concerned concrete entities, within categories such as animals, fruits/vegetables, tools/utensils, body parts, and

The authors would like to acknowledge the substantial artistic contributions of Chuck Kaloustian and Susan Bakker in the development of the stimulus materials, and the willingness of Susan Bakker and the Jane and Jim Cerhan family to appear as subjects in many photographs. This work was supported by NINDS PO NS19632. J.A.F., who is affiliated with the Departments of Neurology at lowa and at Washington University, received additional fellowship support from the Charles A. Dana Foundation. Correspondence concerning this paper and requests for copies of the stimulus materials should be addressed to $D$. Tranel, Department of Neurology, 200 Hawkins Drive, University of lowa Hospitals and Clinies, lowa City, IA 52242. so on. The study of retrieval of knowledge for actions, in terms of both conceptual knowledge (i.e., retrieving information about the meaning of actions) and lexical knowledge (i.e., retrieving the words for actions) has lagged behind. Only a few reports regarding action naming have been published, and there are very few studies regarding. the retrieval of conceptual knowledge for actions. ${ }^{2}$

One factor that has limited investigations of the retrieval of lexical and conceptual knowledge for actions has been the lack of suitable stimulus materials. Only a few naming tests containing pictures of actions have been developed (e.g., Gertmann, 1990; Obler \& Albert, 1982), and these tests have several limitations: (1) they contain relatively few items, (2) limited normative information about the stimuli is available, (3) the stimuli elicit a limited range of responses - primarily high-frequency intransitive verbs in present-tense gerundial forms. Even fewer materials are available for evaluating the retrieval of conceptual knowledge for actions. In response to this need, we have developed a set of standardized tests for evaluating the retrieval of lexical and conceptual knowledge for actions.

\section{Development of Stimulus Materials}

Our development of stimulus materials was guided largely by the fact that the organization of conceptual knowledge for actions, and the lexical forms denoting this knowledge, have been discussed from a variety of perspectives. (For greater readability, we will refer to lexical forms denoting actions as verbs, although they can also 
be used as past participles [e.g., flying fish] and gerunds [e.g., the dialing of the phone woke him].) Each of these perspectives is supported by theoretical and empirical work, suggesting that a variety of semantic and syntactic factors should be considered in the development of a stimulus set suitable for exploring the retrieval of lexical and conceptual knowledge of verbs.

One factor is the nature of the conceptual relationships between verbs. One approach to this issue has been to decompose each verb into semantic primitives (see, e.g., Jackendoff, 1983, 1990); a second approach has been to organize verbs into categorical hierarchies with specific types of interrelations (e.g., Miller \& Fellbaum, 1991). Both approaches have provided theoretical insight into the complex lexical-semantic organization of verbs. For instance, Miller and Fellbaum found that verb semantic categories tend to have a shallow hierarchical structure (with most categories having fewer than four levels) and that, generally, one level in the hierarchy is disproportionally large. Furthermore, Miller and Fellbaum emphasized that in addition to relationships between verbs within a particular category (e.g., STROLLING is a subordinate of WALKING), there are also a number of important relationships between verbs in different categories (e.g., SNORING entails SLEEPING). Hence, it is not surprising that empirical investigations have found considerable variability in how subjects categorize verbs (Fisher, Gleitman, \& Gleitman, 1991; Miller, 1972). These factors in the conceptual organization of verbs led us to depict exemplars from a broad range of categories, rather than restrict our focus to the depiction of multiple exemplars from a relatively limited number of categories. Furthermore, given evidence that category-specific recognition or naming defects for concrete entities typically occur at the basic object level (e.g., RACCOON), rather than the superordinate level (e.g., ANIMAL) (A. R. Damasio \& H. Damasio, 1993; A. R. Damasio et al., 1990; Silveri, Giustolisi, \& Gainotti, 1991; Warrington \& McCarthy, 1987), we also attempted to ensure that subordinate members of general conceptual categories were represented (e.g., GALLOPING as an exemplar of RUNNING; DICING as an exemplar of CUTTING).

Another consideration is the strong relationship between semantics and syntax (Chomsky, 1957; Grimshaw, 1990; Gruber, 1976; Jackendoff, 1983, 1990; Pinker, 1989). As elucidated by Chomsky, among others, an important feature of verbs is that they can be classified not only according to their meaning, but also according to the type of arguments that they require in order for one to produce a grammatical sentence. Furthermore, each of the arguments accepted by a particular verb may play one of a limited number of thematic roles (such as specifying the agent performing the action or the person or thing undergoing the action) (see, e.g., Fillmore, 1968; Jackendoff, 1987). The relationship between syntax and semantics has also been demonstrated empirically. For instance, it has been shown that children are sensitive to argument structures in the acquisition of new verb forms (see, e.g., Behrend, 1990; Gropen, Pinker, Hollander, \& Goldberg,
1991; Naigles \& Kako, 1993). Furthermore, Levin and colleagues (Levin \& Hovav, 1991; Levin \& Rappaport, 1991) have theorized that at least some classes of verbs can be classified into semantic categories on the basis of their argument structures. In developing the stimulus materials, we attempted to depict actions and events that would support a variety of thematic roles and that could elicit verbs with different argument structures.

A third factor concerns the neural systems that appear to be involved in the retrieval of conceptual knowledge for actions and events. As noted by A. R. Damasio and Tranel (1993), the neural systems that mediate access to verbs appear to be anatomically linked to the systems that support concepts of movement and relationships in space-time (such as the somatosensory, premotor, and motor cortices). Thus, conceptual knowledge of actions, and retrieval of the lexical forms that denote such knowledge, may be intimately tied to the process of representing visual and somatosensory aspects of the motion of a concrete entity, both intrinsically and in space-time (A. R. Damasio \& H. Damasio, 1993; A. R. Damasio \& Tranel, 1993; Klatzky, Pellegrino, McCloskey, \& Lederman, 1993; Martin, Haxby, Lalonde, Wiggs, Ungerleider, 1995). In order to facilitate the exploration of this hypothesis, we attempted to depict actions that vary along a number of dimensions potentially important for the neural representation of movement in space-time. For instance, the depicted actions differ in terms of the movement trajectories that they involve, the body part utilized to perform an action, and whether a tool is used or an object is manipulated. In addition, we also attempted to include actions and events that vary in terms of the agent performing the action: in many cases, the agent is a person, but in some items, the agent is an animal or an object. We also chose to vary the degree to which the action must be inferred from the displayed pictures. Some items are a static representation of an ongoing action; for others, an action must be inferred on the basis of some change between two pictures. Importantly, these two different types of stimuli also serve to further the goal of creating stimuli that vary syntactically. For items depicting an ongoing action, gerundial (-ing) forms are elicited (e.g., WALKING); in contrast, for items in which the action must be inferred through comparison of two pictures, past-tense forms are produced (e.g., CHOPPED).

In order to create a broad range of stimuli, we began by creating a list of all verbs from Francis and Kučera (1982) which we believed could be depicted visually in a static image (thus excluding verbs such as AMBLING and SPECULATING). Next, we attempted to create stimuli depicting each of the verbs on this list. The majority of the stimuli were created by photographing staged scenes of actions or events. We attempted to maintain visual similarity across stimuli by using a small number of actors and photographic backgrounds. We also attempted to keep the visual complexity of the photographs to a minimum by focusing only on the part of the scene that was necessary to convey the intended action. Color photographs were chosen rather than line drawings, because it 
was felt that such photographs would convey more accurately and efficiently processes that occur through space and time, using two-dimensional, static images. For actions that were difficult to stage in the laboratory (e.g., galloping, skiing), stimuli were adapted from published materials. Single photographs were used to depict persons, animals, and objects engaged in ongoing actions. Photograph pairs were used to depict a change of state or event: one member of the pair showed a person, object, or animal before something happened (e.g., a piece of raw meat), and the other showed the same person, object, or animal after some change or event (e.g., a piece of cooked meat). ${ }^{3}$

Over 900 stimuli were created and, in a pilot study, naming responses to each of the stimuli were elicited from 5-40 undergraduate psychology subjects. Data from this pilot study guided the selection of items for standardized naming and conceptual knowledge tests. Such screening was important, because it was anticipated that a sizeable number of stimuli would be unsuitable for a standard test of naming. For instance, because of the semantic and syntactic structure of verbs, many actions that can be clearly depicted elicit several different responses, all of which are appropriate. For example, a picture of a person stacking a set of wooden blocks elicited the target response of STACKING, as well as BUILDING, CONSTRUCTING, and PLAYING. To develop a test that could be used to measure with precision the action-naming capacities of subjects, however, we needed to develop items that for the most part would elicit only a few $(1-3)$ predominant responses from normal subjects.

\section{Development of a Naming Test to Assess Lexical Retrieval}

We selected 280 items for a standard test of action naming. One of our goals was to include stimuli that were clear representations of target actions and that elicited, at most, three predominant responses. As discussed above, a second goal was to include stimuli that varied along several syntactic and conceptual dimensions. In brief, the stimuli vary syntactically in terms of: (1) the inflection of the elicited response (gerundial vs. pasttense forms) and (2) the compatibility of the elicited response with different argument structures (i.e., some elicited responses can only be produced in a well-formed sentence as an intransitive [one-place predicate] verb [e.g., "Jane is smiling"], some only as a transitive/ditransitive [two- or three-place predicate] verb [e.g., "Jane is arranging the flowers," or "John is giving a flower to Jane"], and some in either type of argument structure [e.g., "Jane is vacuuming," or "Jane is vacuuming the carpet"]). The stimuli also vary in terms of (1) semantic category (e.g., types of motion, contact, perception, creation; Miller \& Fellbaum, 1991), (2) the type of agent performing each action (e.g., person vs. animal), and (3) the frequency of the action (as judged by the frequency of the elicited response as a verb per million written words; Francis \& Kučera, 1982).
The 280 items were evaluated in two experiments. In Experiment 1, the naming response elicited by visual presentation of each item was investigated in 64 subjects, and normative information from 40 subjects was obtained for each of three other variables: visual complexity, familiarity, and image agreement. These variables were chosen in part because they have been important in the development and utilization of stimuli depicting concrete entities (Snodgrass \& Vanderwart, 1980). Also, in collecting these normative data, we had two goals in mind. One was to facilitate future research in which the stimuli might be used to study cognitive processes other than the retrieval of lexical information. Pictorial stimuli have been used in the investigation of many different aspects of visual, linguistic, and mnemonic processing. In the past, such research has relied almost exclusively on depictions of concrete entities, partly because of the lack of suitable stimuli depicting actions. A second goal was to use the information from Experiment 1 to develop standard administration and scoring procedures for using the 280 items to evaluate the retrieval of specific lexical forms denoting actions. These procedures will be described and evaluated in Experiment 2.

\section{Development of Tests to Assess the Retrieval of Conceptual Knowledge}

As alluded to earlier, subjects may be unable to retrieve lexical information for a stimulus (i.e., they cannot name it), even though they are still able to retrieve conceptual knowledge about that stimulus (i.e., they can recognize it). In fact, such dissociations have been reported previously for the naming and recognition of concrete entities (e.g., A. R. Damasio et al., 1990) and have formed the cornerstone for understanding the neural underpinnings of word retrieval and concept retrieval processes. In Experiment 3, we describe the development of a set of tests that can be used to evaluate the retrieval of conceptual knowledge for actions.

Five tests were developed. In creating the tests, we had several general considerations in mind. One goal was to develop tests for which the responses could be made nonverbally, so as to disentangle the process of word retrieval from the process of concept retrieval. A second goal was to create tasks with both words (spoken and written) and pictures as stimuli, in order to explore whether naming or concept retrieval difficulties might be attributable to problems with the visual perceptual analysis, pictures being more complicated to analyze perceptually than words. Dissociations in the ability of brain-damaged patients to retrieve different types of conceptual knowledge for concrete entities have been reported. For instance, some subjects may be able to correctly identify the superordinate category for a concrete entity (e.g., a banana is a type of fruit), but may be unable to make judgments about attributes associated with the entity (e.g.. a banana is yellow) (Bayles, Tomoeda, \& Trosset, 1990; Goodglass \& Baker, 1976; Martin \& 
Fedio, 1983; Warrington, 1975). For this reason, a third goal was to assess conceptual knowledge for both similarities and differences between actions, and for the attributes associated with actions.

The specific tests that we developed were based on tasks previously used to explore the retrieval of concep- tual knowledge for concrete entities (Bayles et al., 1990; A. R. Damasio et al., 1990; Goodglass \& Baker, 1976; Martin \& Fedio, 1983; McCarthy \& Warrington, 1985; Warrington, 1975). A picture-word matching task was developed in order to explore the association between conceptual knowledge and word recognition. An at-
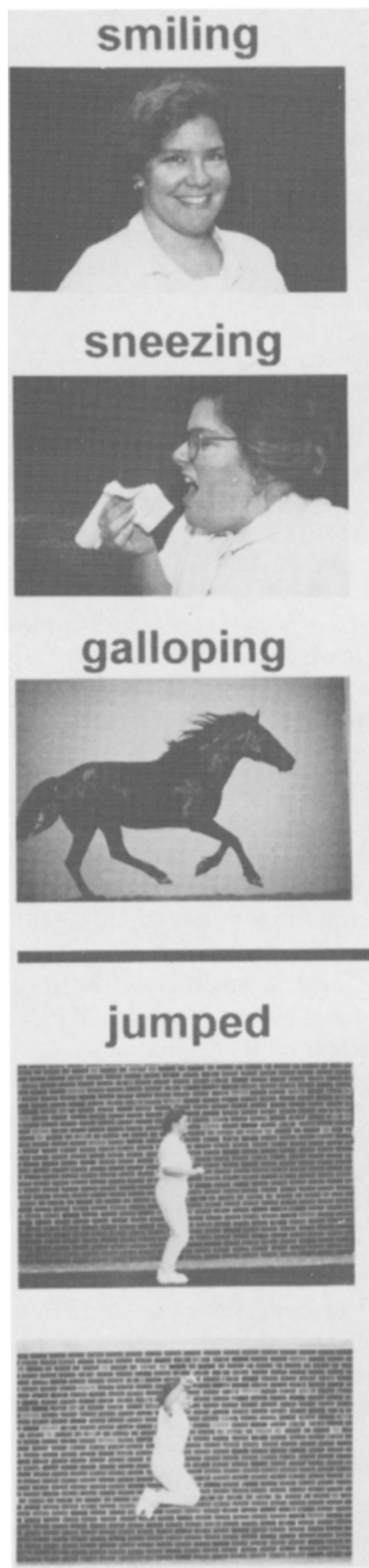

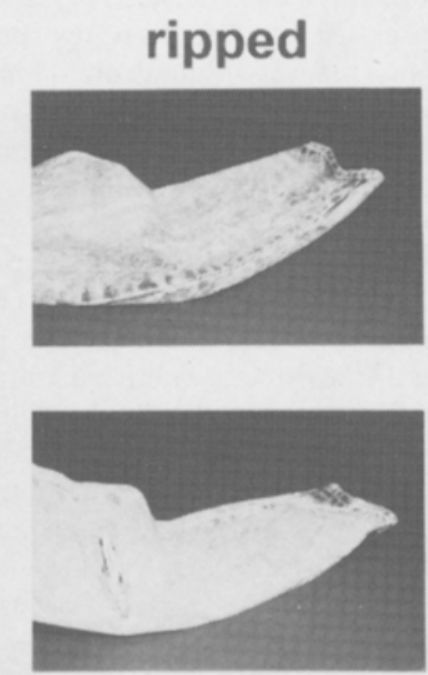

sewing

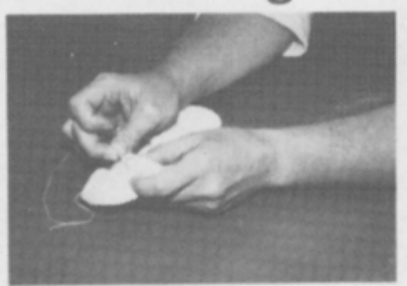

saluting

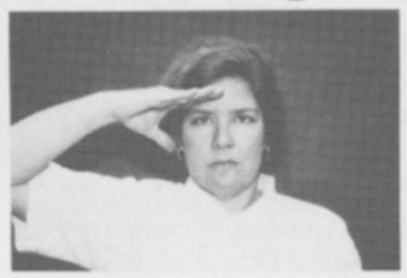

rolling
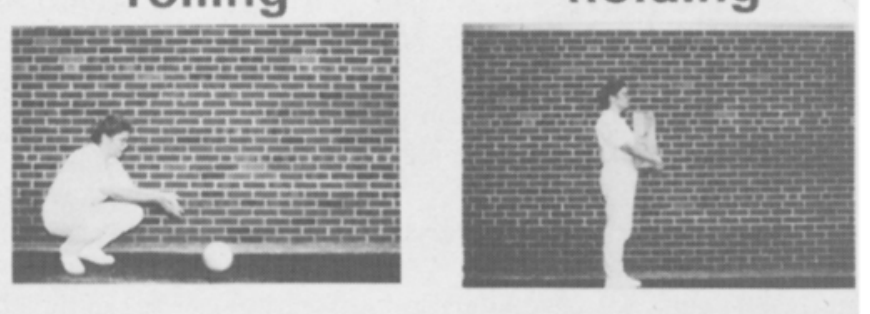

crumpling

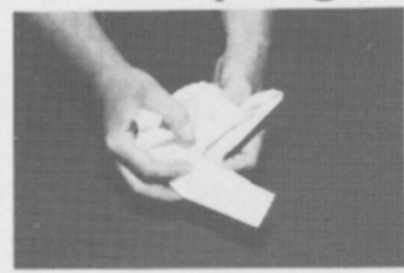

holding

\section{chopped}
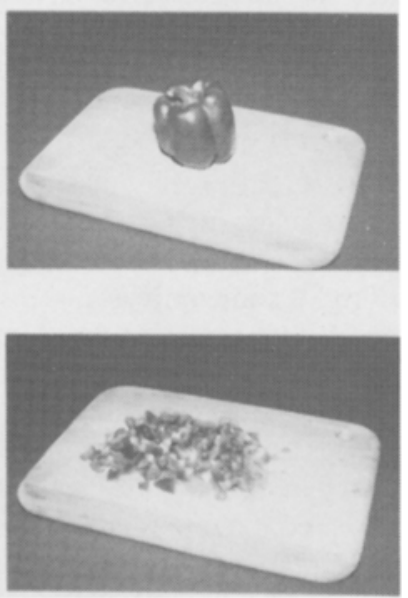

Figure 1. Examples of stimuli depicting actions and events. Note that the stimuli vary according to (1) inflectional form (SMILING vs. CHOPPED), (2) frequency (CRUMPLING vs. JUMPED), (3) agent (SMILING vs. GALLOPING), and (4) potential transitivity (SNEEZING vs. MIXING). Although the picture pairs (bottom) are shown above and below each other, for all testing they were presented side by side. 
tribute knowledge task in which subjects select which of two pictures or which of two words best matches certain criteria (e.g., Which makes the loudest sound?) was used to assess whether subjects could access information about different types of attributes associated with actions. A stimulus comparison task, in which subjects select the picture or word that is least related to two other pictures or words, was developed in order to evaluate the retrieval of information about conceptual relationships between actions.

Potential pictorial items for the tests were drawn from the pool of over 900 stimuli that we had developed. Many of the potential words represented the target responses elicited by each of these stimuli. The correct responses for the tests were defined empirically in a pilot study involving 86 undergraduates. Stimuli for which $70 \%$ or more of the subjects in the pilot study selected the same response (thus defining the "correct" response) were selected for inclusion in the final versions of each test. Once the stimuli and procedures for each test were finalized, they were evaluated in a new group of subjects, as will be reported in Experiment 3.

\section{EXPERIMENT 1}

\section{Method}

Subjects. A total of 184 subjects participated in experiments involving the naming and perceptual rating of stimuli. Of these, 64 participated in an experiment that evaluated the naming responses elicited by pictures of actions, and 120 participated in three different experiments ( 40 subjects per experiment) involving the rating of action stimuli on several perceptual dimensions. The subjects were undergraduate students in an introductory psychology class. They received course credit for their participation. All were native English speakers. The subjects were tested in groups of 10-20 in a classroom.

Stimulus materials. The stimulus materials consisted of the 280 items selected for inclusion in a standard test of action naming. For examples of the stimuli, see Figure 1. Single pictures were used to depict persons, animals, and objects engaged in ongoing actions. Picture pairs were used to depict a change of state or event: one member of the pair showed a person, object, or animal before something happened (e.g., a piece of raw meat), and the other showed the same person, object, or animal after some change or event (e.g., a piece of cooked meat). As noted in the introduction, the stimuli were selected to vary along several dimensions, summarized in Table 1.

Procedure. The pictures were sequentially projected onto one or two screens at the front of a slightly darkened room. For items consisting of a picture pair, the picture depicting a person or object prior to some event was shown on a screen to the left of the subjects, and the picture depicting the same person or object after some event was shown simultaneously on the screen to the right of the subjects. All 280 items were shown to each subject group. The single-picture items were divided into three different carousels, while the picture pair items were placed into a single pair of carousels (one carousel of the pair containing the "before" pictures, and the other containing the "after" pictures). The items shown to each subject group were always grouped by format type: that is, all of the 210 singlepicture items (depicting ongoing actions) were shown sequentially, followed (or preceded) by all of the 70 picture pair items (depicting persons and objects before and after some action). Different sequences of items were created by varying, across subject groups, the order in which (1) the different formats were presented, (2) the
Table 1

Item Characteristics Across Selected Dimensions

\begin{tabular}{lr} 
Characteristic & No. Items \\
\hline Source & \\
$\quad$ Original & 222 \\
$\quad$ Adapted & 58 \\
Agent & \\
$\quad$ Person & 242 \\
Animal & 14 \\
Object & 24 \\
Frequency & \\
High ( $>50)$ & 88 \\
Medium (10-50) & 116 \\
Low ( <10) & 76 \\
Inflectional form & \\
Gerundial (-ing) form & 210 \\
Past tense form & 70 \\
Potential transitivity & \\
Transitive/ditransitive & 119 \\
Transitive or intransitive & 75 \\
Intransitive & 86
\end{tabular}

Note-Items were categorized according to the photographic source, the type of agent performing the depicted action, the frequency of the elicited response as a verb per million written words (Francis \& Kučera, 1982), the inflected form of the elicited response, and the potential transitivity of the elicited response.

three slide carousels containing the single picture items were presented, and (3) the slides in each carousel were presented (by moving the carousel in the forward or the backward direction).

At the start of each task, subjects were told that they would be asked to name or to rate, on the basis of a particular characteristic, a series of pictures of actions. The subjects were encouraged to respond carefully and consistently. Each subject group was asked to perform one of several tasks, described in greater detail below. The rating tasks and the instructions were modeled on the procedures used by Snodgrass and Vanderwart (1980) to evaluate different aspects of a series of 260 line drawings of concrete entities.

Naming. For items consisting of a single picture, subjects were told to look at each picture and to write down a single word that best described what the person, animal, or object was doing. For items consisting of a picture pair, subjects were told that the picture shown to their left would depict a person or object before some action, and that the picture shown to their right would depict the same person or object after some action. They were told to look at each pair, and to write down a single word that best described what was done to each object, or what each person or object did. The subjects were told to leave a blank line in instances in which they were unable to provide an answer. Each picture or picture pair was presented until it appeared that all subjects had completed writing a response (approximately $5 \mathrm{sec}$ per item). Three examples of each stimulus type (single-picture and picture pair format), along with example naming responses, were given in order to illustrate the types of items that would be shown and the types of responses that they might elicit.

Familiarity. Subjects were asked to judge the familiarity of the action depicted in each picture or picture pair "according to how usual or unusual the action is in your realm of experience." Familiarity was defined as "the degree to which you come in contact with or think about the concept." They were told to rate the action itself, rather than the way in which it was photographed or the particular object used to demonstrate the action. A 5-point rating scale was used in which 1 indicated very unfamiliar actions, and 5 , very familiar actions. In this and the other rating tasks, the subjects were told to assign only one whole-number value to each picture and were encouraged to employ the full range of scale values through- 
out the set of pictures. In order to give the subjects a sense of the variability across items, they were first instructed to merely look at, without making any ratings, the first 20 single-slide format items and the first 10 double-slide format items in the sequence. Following this initial presentation, the subjects began their rating, starting with the first item in the sequence. Each slide or slide pair was presented for approximately $4 \mathrm{sec}$.

Visual complexity. Subjects were told to rate the complexity of each picture or picture pair on a 5-point scale in which 1 indicated very simple, and 5 , very complex. Complexity was defined as the amount of detail or intricacy in the photograph(s). They were told to rate the complexity of the photograph itself rather than the complexity of the real-life action that it represented. In order to give the subjects a sense of the variability across items, they were first instructed to merely look at, without making any ratings, the first 20 single-slide format items and the first 10 double-slide format items in the sequence. Each slide or slide pair was presented for approximately 4 sec.

Image agreement. Subjects were asked to judge how closely each picture resembled their mental image of the action. Prior to presenting each picture, the experimenter called out the picture's target name, waited approximately $3 \mathrm{sec}$, and then projected the picture or picture pair on the screen. (For items in which there was more than one target response [see Appendix C], the most frequently produced response was called out. For items in which predominant target response was not the most frequently elicited response [see Appendix B], for half of the subjects the experimenter called out the target response, and for the other half the experimenter called out the predominant response.) During the 3 -sec waiting period, the subjects were instructed to form a mental image of the named action. Following the appearance of the picture or picture pair, the subjects rated the degree of agreement between their image and the stimulus item on a 5-point scale, and they were given approximately $3 \mathrm{sec}$ to respond. A rating of 1 indicated low agreement that the picture provided a poor match to their image, and a rating of 5 , high agreement. At the start of the session, the subjects were informed of the general nature of the pictures and were provided with four examples in the single-slide format and four examples in the doubleslide format.

\section{Results (Table 2) and Discussion}

The naming responses produced by the 64 subjects to each of the 280 stimuli are listed in Appendix A (digitized copies of all stimuli are available upon request).
These responses were analyzed in greater detail, following the procedures used by Snodgrass and Vanderwart (1980) to analyze responses elicited to a set of 260 line drawings of concrete entities. As one measure of name agreement, for each item the percentage of subjects who gave a specific predominant target response (see Appendix B) was computed. In a few instances, the target response represents the most accurate and precise name for a stimulus, although it is not the predominant response (e.g., GALLOPING vs. RUNNING). As a second measure of name agreement, the information statistic $H$ was computed for each picture with the following formula:

$$
\stackrel{k}{H}=\sum p_{i} \log _{2} \frac{1}{p_{i}},
$$

where $k$ refers to the number of different names given each picture, and $p_{i}$ is the proportion of subjects giving each name. Failures to produce a name (a null response) were treated as a type of name, as were different inflectional forms of a particular verb. Misspellings of a particular verb were included with correct spellings of the verb when $H$ was computed.

The $H$ statistic has the advantage of carrying information about the distribution of responses across subjects (Snodgrass \& Vanderwart, 1980). A stimulus named identically by all 64 subjects would have an $H$ value of 0 . Increasing $H$ values indicate decreasing name agreement and, usually, decreasing percentages of overlapping responses. Take, for instance, two items that are both given the target name by 60 of the subjects, with one of the items given a single other name by the remaining 4 subjects, and the other given four other names, each by a single subject. The two items will have equal percent agreement scores, but the first will have a lower $H$ score than the second (.34 vs. .46).

Items statistics for the percent agreement and $H$ values (derived from a total of 64 subjects) and the perceptual ratings of familiarity, visual complexity, and image agreement (derived from a total of 40 subjects for each

Table 2

Summary Statistics for Normative Ratings From Experiment 1, Including Mean Values for Familiarity, Visual Complexity, and Name Agreement Ratings

\begin{tabular}{|c|c|c|c|c|c|c|c|}
\hline & $\begin{array}{c}H \\
(0-6) \\
\end{array}$ & $\begin{array}{c}\% \\
\text { Agreement } \\
(0-100)\end{array}$ & $\begin{array}{c}\text { Familiarity } \\
(1-5)\end{array}$ & $\begin{array}{c}\text { Visual } \\
\text { Complexity } \\
(1-5)\end{array}$ & $\begin{array}{c}\text { Image } \\
\text { Agreement } \\
(1-5)\end{array}$ & $\begin{array}{c}\text { Word } \\
\text { Frequency } \\
(0-2,765)\end{array}$ & $\begin{array}{c}\text { Word } \\
\text { Frequency } \\
\text { (Cubed Root) } \\
(0-14)\end{array}$ \\
\hline $\begin{array}{l}M \\
S D\end{array}$ & $\begin{array}{l}1.15 \\
0.87\end{array}$ & $\begin{array}{l}74 \\
24\end{array}$ & $\begin{array}{l}3.16 \\
0.73\end{array}$ & $\begin{array}{l}2.55 \\
0.79\end{array}$ & $\begin{array}{l}4.12 \\
0.62\end{array}$ & $\begin{array}{r}75 \\
138\end{array}$ & $\begin{array}{l}3.32 \\
1.80\end{array}$ \\
\hline $\begin{array}{l}\text { Median } \\
\text { Ist quartile } \\
\text { 3rd quartile } \\
\text { Quartile range }\end{array}$ & $\begin{array}{l}0.94 \\
0.44 \\
1.80 \\
1.36\end{array}$ & $\begin{array}{l}83 \\
56 \\
94 \\
38\end{array}$ & $\begin{array}{l}3.17 \\
2.65 \\
3.70 \\
1.05\end{array}$ & $\begin{array}{l}2.34 \\
1.98 \\
2.88 \\
0.90\end{array}$ & $\begin{array}{l}4.28 \\
3.78 \\
4.58 \\
0.80\end{array}$ & $\begin{array}{r}28 \\
9 \\
72 \\
62\end{array}$ & $\begin{array}{l}3.05 \\
2.08 \\
4.14 \\
2.07\end{array}$ \\
\hline $\begin{array}{l}\text { Minimum } \\
\text { Maximum } \\
\text { Skewness }\end{array}$ & $\begin{array}{l}0.00 \\
3.64 \\
1.75 \\
\end{array}$ & $\begin{array}{r}0 \\
100 \\
0.41 \\
\end{array}$ & $\begin{array}{l}1.53 \\
4.85 \\
1.04 \\
\end{array}$ & $\begin{array}{l}1.25 \\
4.70 \\
1.50 \\
\end{array}$ & $\begin{array}{l}1.70 \\
4.98 \\
0.60\end{array}$ & $\begin{array}{r}0 \\
1264 \\
2.32 \\
\end{array}$ & $\begin{array}{r}0.00 \\
10.79 \\
1.39\end{array}$ \\
\hline
\end{tabular}

Note-The potential range of each statistic is indicated below each column heading. Skewness $=(3 \mathrm{rd}$ quartile - Median)/(Median - 1st quartile). Transformed word frequencies (cubed root) were computed by taking the cubed root of the frequency values from Francis \& Kučera (1982), in order to transform the frequency values into a normal distribution. 
Table 3

Correlations Among the Measured Variables

\begin{tabular}{|c|c|c|c|c|c|}
\hline & $H$ & $\begin{array}{c}\text { Image } \\
\text { Agreement }\end{array}$ & Familiarity & $\begin{array}{c}\text { Visual } \\
\text { Complexity }\end{array}$ & Frequency \\
\hline$H$ & 1.0 & & & & \\
\hline Image agreement & -.41 & 1.0 & & & \\
\hline Familiarity & -.37 & .30 & 1.0 & & \\
\hline Visual complexity & .25 & -.10 & -.55 & 1.0 & \\
\hline Frequency (cubed root) & -.11 & -.23 & .28 & -.23 & 1.0 \\
\hline
\end{tabular}

rating) are provided in Appendix B. In addition, frequency counts are also provided; these are based on the Francis-Kučera (1982) norms. The listed value is the total occurrence of the target response stem across inflectional uses of the verb. Occurrences of the word stem in different grammatical classes were excluded. This assessment of frequency was felt to correspond most closely to familiarity of the action represented by each target response. Summary statistics for each measured variable are provided in Appendix B.

For the 280 stimuli, the distribution of $H$ values had a low mean (1.15) and was positively skewed, reflecting the fact that there was high name agreement for many of the depicted actions. The ratings of image agreement had a high mean and were negatively skewed, indicating a tendency for subjects to agree that their visual images matched the stimuli. The mean rating of familiarity was near the midpoint, with a slightly positive skew. The ratings of complexity had a low mean and a strong positive skew. This indicates that subjects had a tendency to regard most images as fairly low in complexity, although the range of values $(1.25-4.70)$ indicates that they used the full range of the scale in evaluating the items.

The Francis-Kučera (1982) frequencies of the target responses were positively skewed, and the resulting mean value reflects the contributions of a relatively low number of items with very high frequencies. Following the approach of Snodgrass and Vanderwart (1980), a cube root transformation was used to transform the frequency values into a normal distribution.

Correlations among the measures. As a means of examining the relationships between name agreement, familiarity, visual complexity, image agreement, and transformed word frequency, the correlations between these different variables were computed. The resulting values are provided in Table 3. As found by Snodgrass and Vanderwart (1980), most of the correlations were of fairly low magnitude, suggesting that the measures represent fairly independent attributes of the stimuli.

Although most of the correlations are low, it is worth noting that the results in the present study, and those found by Snodgrass and Vanderwart (1980), are quite similar. This suggests that there may be commonalities in picture processing and lexical retrieval which extend across grammatical domains. For instance, despite differences between types of concepts (entities vs. actions) and format (line drawings vs. color photographs), in both the present study and that of Snodgrass and Vanderwart, the largest correlation was that between familiarity and visual complexity. As discussed by Snodgrass and Vanderwart, one explanation is that familiar concepts are spoken of and thought about frequently, and efficient verbal and visual codes have been developed to express them.

Sources of name disagreement. Though overall name agreement was relatively high, greater variability was found in the present study than in Snodgrass and Vanderwart (1980). We believe that this variability reflects features specific to the conceptual organization of verbs, and that it would be inherent to any stimulus set that depicted a broad range of actions. Support for this interpretation comes from examining the types of names that subjects provided when they failed to give a target response.

In examining the sources of name disagreement, we began by classifying the nontarget responses obtained in the present study into the categories used by Snodgrass and Vanderwart (1980) to evaluate nondominant responses to pictures of concrete entities. These categories were the following: synonyms, coordinates, superordinates, subordinates, and naming failures (no response). For verbs, whether two verbs can be regarded as synonyms is partially context dependent (Miller \& Fellbaum, 1991). Thus, synonyms were defined as verbs that could be used interchangeably to describe a particular action as shown in a picture or picture pair (e.g., CHOKING vs. STRANGLING). Coordinates were defined as different exemplars of the same category (e.g., SEWING and KNITTING). Superordinates included responses such as CUTTING for CHOPPING, EATING for GRAZING, etc. Subordinates were defined as a subclass of the pictured actions (e.g., NAPPING for SLEEPING Or STROLLING for WALKING).

Relative to nondominant names provided for pictures of concrete entities (Snodgrass \& Vanderwart, 1980), the types of nontarget responses provided for our pictures of actions differed in two important respects. First, for the responses that fell into the categories utilized by Snodgrass and Vanderwart, the proportion of entity naming versus action naming responses in each category differed. The largest difference was a greater tendency for subjects to give superordinate responses for pictures of actions, relative to pictures of concrete entities ( $42 \%$ vs. $11 \%$ ). These differences may very well reflect differences in the ability to group nouns versus verbs into tree-like semantic hierarchies (Miller \& Fellbaum, 1991), and support other evidence that there is less consensus among subjects as to the basic categorical level at which to describe a particular action (Fisher et al., 1991; Miller, 1972).

A second difference is that while all of the nontarget responses reported by Snodgrass and Vanderwart (1980) 
could be classified as a synonym, coordinate, superordinate, or naming failure, in the present study this was true for only about half $(48 \%)$ of the nontarget responses. Clearly, these categories are inadequate to capture many of the relationships that exist between actions and that give rise to name disagreement. This is most clearly illustrated by considering actions that involve a relationship between two animate objects, each of which can be interpreted as the agent of some action. Different names can thus be provided for the action, depending on the chosen perspective (e.g., GIVING vs. TAKING, RIDING vs. TROTTING). Differences in perspective may also result in the production of different inflectional forms of the same verb to describe some action. For instance, comparison of a picture showing a blank piece of paper with a subsequent picture of the paper containing a drawing may elicit either DREW, referring to some agent not shown in either picture, or DRAWN, referring to the drawing (i.e., it was drawn) or to the paper (i.e., it was drawn upon). Finally, some name disagreement arises from more complex relationships between actions. For instance, some actions consist of a part/whole relationship (e.g., a part of playing cards is dealing the cards, a part of crying might be wiping your nose), and some actions also entail another action (e.g., snoring entails sleeping) (Miller \& Fellbaum, 1991). Once again, different names may arise, depending on the perspective taken by the subject. Although some of these sources of name disagreement can be reduced by careful selection of stimulus items, in situations where subjects freely choose the perspective from which to view a scene, they cannot be completely eliminated.

As a final source of variability, it should be noted that name disagreement also arises from apparent failures in the retrieval of lexical or conceptual knowledge. For concrete entities, when subjects failed to recognize an item correctly, they were most likely to produce a naming failure or a coordinate (Snodgrass \& Vanderwart, 1980). For actions, subjects appeared to resort to a variety of strategies, including the creation of new words (e.g., DEWOOLING instead of SHEARING) and the inaccurate use of existing words (e.g., THREADING in response to KNITTING, TORN in response to FRAYED), which are neither coordinates nor superordinates of the target response.

Nonetheless, it is important that the variability in name agreement is not evenly distributed. Of the 4,773 nontarget responses found in Experiment 1, 68\% were "atypical" responses produced by fewer than $5 \%$ of the subjects. The frequency of the remaining nontarget responses is more evenly distributed (for instance, only $9 \%$ of the nontarget responses were produced by $5 \%-10 \%$ of the subjects). On the average, 4.4 "atypical" responses were produced per item, while overall only 2.1 responses per item were produced by $5 \%$ or more of the subjects. In fact, differences in the frequency distribution of nontarget responses accounted for most of the increased response variability found in the present study, as compared with the results reported by Snodgrass and Vanderwart
(1980). In Snodgrass and Vanderwart, an average of only 1.1 "atypical" responses were produced per item, while 1.4 responses per item were produced by $5 \%$ or more of the subjects.

These findings had important implications for our development of a standard test suitable for evaluating the retrieval of well-defined target responses denoting actions. As discussed above, for some items the sources of response variability cannot be completely eliminated when one uses the naming procedures employed in this experiment. A pilot study involving 17 subjects confirmed that the potential agreement for some stimulus items could be significantly enhanced by (1) directing subjects' attention to a particular agent or object by pointing to a part of the picture and (2) encouraging subjects to provide a second response through the utilization of specific prompts. Second, in order to evaluate performance on the test objectively, we wished to define a relatively restricted set of "correct" responses for each item. To accomplish this goal, we chose to focus on commonly elicited responses. Through the use of these additional administration and scoring procedures, we hoped to develop a standard test that could be used to assess the retrieval of specific lexical forms, in which subjects would not be penalized for producing nontarget responses resulting from differences in the categorical level at which they initially described an action (e.g., CUTTING vs. DICING) or from the perspective that they selected on a depicted action, and which would provide a means of evaluating the responses without posthoc subjective decisions. In Experiment 2, we evaluated the effectiveness and reliability of the administration and scoring procedures that we had developed.

\section{EXPERIMENT 2}

\section{Method}

Subjects. A total of 60 native English-speaking subjects participated in an experiment designed to evaluate the effectiveness and reliability of procedures used for administering and scoring a standard test of action naming. The subjects were tested in a classroom in three groups of 20 students, with each stimulus presented to two of the three groups (giving a total of 40 subjects who responded to each item). The subjects were students in an introductory psychology class, and they received course credit for participation.

Stimuli and Procedure. The stimuli were the 280 items analyzed in detail in Experiment 1 . The naming procedures described in Experiment 1 were modified for some items to (1) cue the subjects' attention to some portion of a photograph, and (2) prompt the subjects for additional responses. Attentional cues were used for items in which the production of nontarget responses was caused by differences in which the person, animal, or object was perceived by subjects to be the agent in a depicted action (e.g., the person giving a flower instead of the person receiving the flower). For these items, the examiner cued subjects by pointing to a particular part of a picture and asking, "What is this person (or object) doing?" or "What is being done with (or to) this?" For some items, the response variability reflected other factors, such as differences in the categorical level at which subjects described a particular action (e.g., cUTTINO vs. CHOPPING). For these items, after all of the subjects had provided an initial response, the subjects were instructed that if they pro- 
duced a specific nontarget response they should try to provide a second answer. Four different types of prompts were used: (1) "kind of" prompts were used to encourage the production of a subordinate response (e.g., "If your first response was cutting, try to produce a second response which specifies what kind of cutting the person is doing."); (2) "single word" prompts were used to encourage the production of a single word synonym (e.g., "If your first response was 'putting together,' try to come up with a single word with the same meaning"); (3) "look again" prompts were used to encourage the subject to look at important visual details in the stimulus (e.g., "If your first response was drawing, look again and see if you can produce a second, more accurate response."); and (4) "besides" prompts were used to encourage the subject to look at a second action depicted in the stimulus (e.g., "If your first response was eating, try to produce a second response describing what else the person is doing").

Scoring. On the basis of the responses elicited in Experiment 1 and the data from the initial screening procedure described in the introduction, for each of the 280 items a set of target responses was defined (see Appendix C). If the subject produced one of the target responses for a stimulus, the response was scored as correct; otherwise, the response was scored as incorrect. Two factors were considered in defining the target responses: (1) whether the response was elicited from $5 \%$ or more of all of the subjects, and (2) whether we judged the response to be an accurate and specific name for the depicted stimulus (e.g., of the responses to a picture of a bucking horse, REARING was not included as a target because it was judged to be inaccurate; JUMPING was not included as a target because it was judged to be too general). The advantage of these scoring procedures was that the response to each item could be evaluated without subjective post hoc scoring procedures. However, in some cases infrequent but accurate responses were scored as incorrect (e.g., STRIDING in response to a picture of a person walking). The response made by each subject to a given item, either initially or following use of a specific prompt, was considered correct if it was one of the target responses.

\section{Results and Discussion}

The percentage of correct responses produced by 40 subjects to each of the 280 stimuli are listed in Appendix $\mathrm{C}$, along with additional information about the use of cues and prompts for each item. The mean percentage of correct responses across all items was $87 \%$. Thus, the 280 items selected for inclusion in the standard test of action naming are sufficiently difficult to avoid ceiling effects among subjects, while at the same time most of the stimuli are correctly named by a large majority of subjects. Furthermore, for items administered identically in Experiments 1 and 2 (i.e., without cues or prompts), the mean percentages of correct responses were nearly identical ( $90 \%$ and $91 \%$, respectively). This result indicates that the scoring procedures produce reliable results across different subject groups.

The effects of cuing and prompting subjects are summarized in Table 4, which compares the percentage of target responses obtained using attentional cues and prompts to the percentage of target responses obtained in Experiment 1 without such cues and prompts. The results demonstrate that for some items the use of cues and prompts enhanced the elicitation of a target response, supporting their use as part of the standard procedure for evaluating the retrieval of specific lexical forms denoting actions. It should be noted that unlike more traditional cuing procedures used in many standard tests of naming (e.g., providing the initial phoneme of a target response), the procedures in the present study were not used to facilitate the retrieval of a target response following a naming failure, but rather to reduce response variability resulting from factors such as the perspective that the subject chose to apply to a depicted action.

\section{EXPERIMENT 3}

\section{Method}

Subjects. A total of 56 subjects participated in a variety of tasks developed to assess retrieval of conceptual knowledge of actions, without requiring the production of verbal responses. The subjects were drawn from the same pool of undergraduate subjects used in the previous experiments. The subjects were tested in groups of $19-22$ in a classroom.

Stimuli and Procedure. As described in the introduction, five tests of action conceptual knowledge retrieval were developed. Pictorial stimuli were used in three of them; these stimuli included most of the 280 items analyzed in Experiment 1, as well as other items drawn from the larger stimulus set of 900 items. Words were used as stimuli in three of the tests; many of these words were drawn from the pool of target responses defined in Experiment 2. In all of the tasks below, the pictorial stimuli were presented in slide format. The pictures that constituted each test item were shown simultaneously for $3-5 \mathrm{sec}$. For the tests that involved words, multiple items were presented on a single page, and the subjects selected the best response for each item at their own pace.

Table 4

Percentage of Target Responses Elicited for Items in Experiment 2 Without Cues or Prompts, With Cues (Given Before Subjects Produced Their First Response), and/or With One of Four Different Types of Prompts (Given After Subjects Produced Their First Response)

\begin{tabular}{|c|c|c|c|c|c|c|c|}
\hline \multirow[b]{3}{*}{ Items } & \multirow[b]{3}{*}{$N$} & \multirow{2}{*}{\multicolumn{2}{|c|}{$\begin{array}{c}\text { Experiment } 1 \\
\text { Response }\end{array}$}} & \multicolumn{4}{|c|}{ Experiment 2} \\
\hline & & & & \multicolumn{2}{|c|}{ Ist Response } & \multicolumn{2}{|c|}{ 2nd Response } \\
\hline & & $M$ & $S D$ & $M$ & $S D$ & $\bar{M}$ & $S D$ \\
\hline No cues/prompts & 166 & 90 & 12 & 91 & 12 & & \\
\hline With a cue & 45 & 55 & 26 & 78 & 18 & & \\
\hline \multicolumn{8}{|l|}{ With a prompt } \\
\hline "Kind of" & 50 & 60 & 25 & 66 & 24 & 79 & 20 \\
\hline "Look again" & 12 & 75 & 21 & 75 & 23 & 87 & 15 \\
\hline "Besides" & 11 & 65 & 25 & 79 & 15 & 84 & 10 \\
\hline "Single word" & 10 & 72 & 17 & 74 & 17 & 78 & 15 \\
\hline
\end{tabular}

Note-None of these items were cued or prompted in Experiment 1, but in Experiment 2 cues and prompts to produce second responses were used for some items. 
As noted in the introduction, the correct responses for the tests were defined empirically as the responses given by most subjects, based on data from a pilot study involving 86 undergraduates. These pilot data were also used to divide the tests into two test forms (Form A and Form B) of approximately equal difficulty and length. Form $A$ from each of the five tests was administered to each 28 subjects, whereas Form B from each of the five tests was administered to a separate group of 28 subjects. Items that had both a picture and a word version were placed into separate forms, and thus no subject was presented with both the picture and the word versions of the same item.

Picture-word matching test. The subjects were asked to select which of two pictures or picture pairs best depicted an action named by the experimenter (see Figure 2). The items were divided into two test forms of 70 items each.

Picture comparison test. The subjects were asked to identify items that depicted similar actions depicted in different contexts (see Figure 2). For each item, the subjects viewed three pictures.
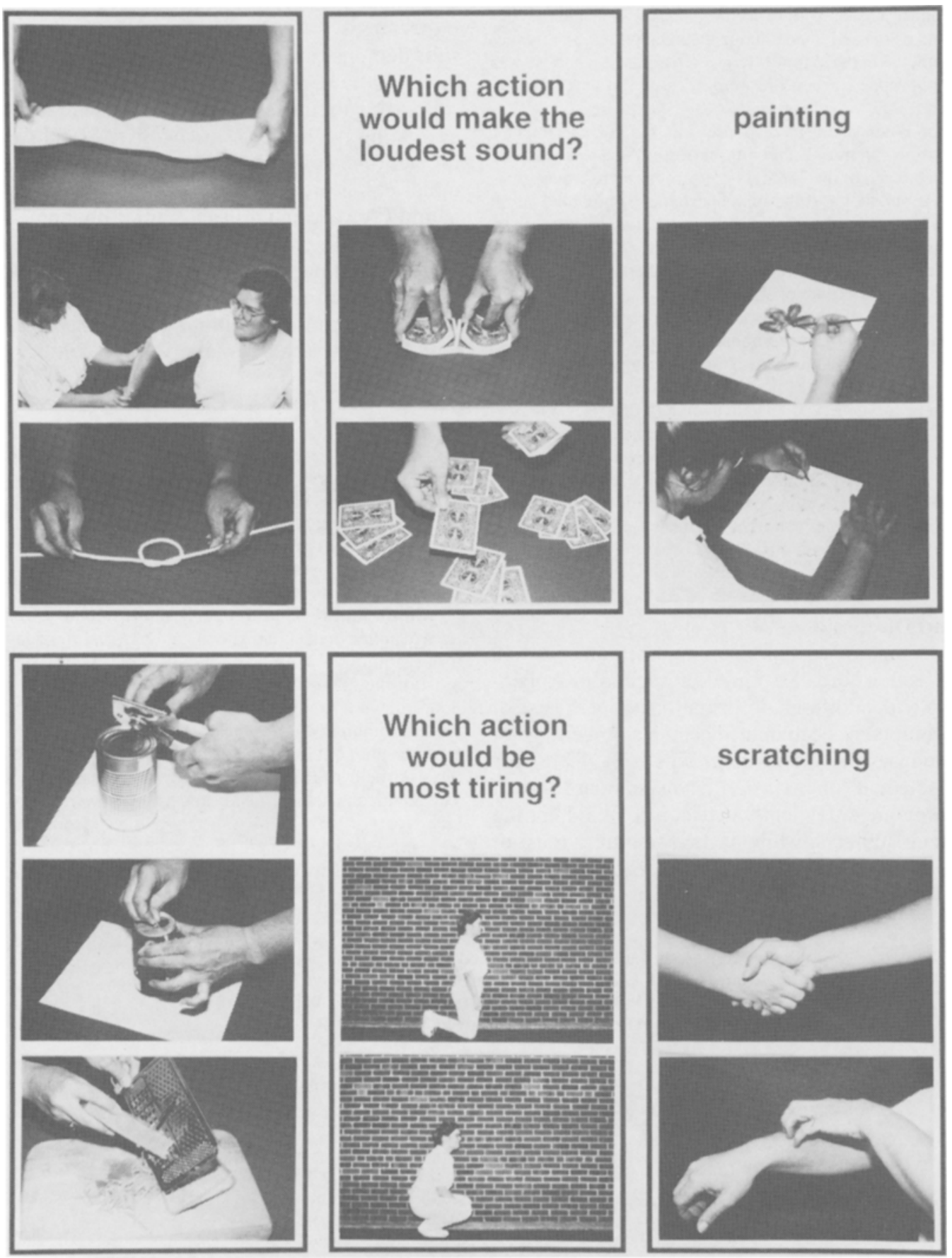

Figure 2. Two representative examples from the picture comparison test (col. 1), picture attribute knowledge test (col. 2), and picture-word matching test (col. 3). 
They were asked to select the picture that showed an action that differed from the other two. An attempt was made to vary the visual similarity between the matching and nonmatching items across the picture trios, so that visual similarity could not reliably be used as a cue for response selection. The items were divided into two test forms of 30 items each.

Word comparison test. Subjects were asked to identify conceptual relationships between written words, thus complementing the picture comparison test described above. For each item, the subjects viewed three words (e.g., the triplet CLENCH, FLEX, and SHRUG, or the triplet START, RACE, FINISH). They were asked to select the word that least "belonged" with the other two. The types of relationships represented by the word triplets were selected from those described by Miller and Fellbaum (1991). In the final version of the test, of the two related words in each triplet, one fourth were synonym pairs, one fourth were antonym pairs, one fourth were coordinates, and one fourth were superordinate/subordinate pairs. The items were divided into two test forms of 48 items each.

Picture attribute knowledge test. Subjects were asked to evaluate attributes of depicted actions. For each item, the subjects viewed two pictures or picture pairs. They were asked to select the picture or picture pair that best met certain criteria (see Figure 2). Across different items, the subjects were asked to apply the following criteria: (1) which action would make the loudest noise, (2) which action would be most physically tiring, (3) which action would take the longest time to complete, (4) which action would require a specified kind of movement, (5) which action would be most enjoyable, harmful, or helpful, (6) which change of state was accomplished using a tool or utensil, (7) which change of state was most permanent, and (8) which change of state best represented an improvement to the object. The items were divided into two test forms of 75 items each.

Word attribute knowledge test. This test was designed to be a written analogue to the picture attribute knowledge test. The subjects were asked to select which of two words best met certain criteria. The words were selected by substituting the pictures used in the picture conceptual knowledge test with their names. Items for which performance was better than $75 \%$ agreement among subjects in a preliminary study were included in the word conceptual knowledge test. The items were divided into one 56 -item and one 65 -item test form. The items on each form were arranged so that they corresponded to the items on one of the two picture conceptual knowledge test forms; therefore, a form of the word conceptual knowledge test can be administered without prior exposure to the items in a pictorial form.

\section{Results}

The summary statistics for each test are listed in Table 5. The mean level of performance across the different tests was similar, with levels of performance on all tests sufficiently low as to reduce the possibility of ceiling effects in other applications. These new tasks should permit the investigation of retrieval of conceptual knowl-

Table 5

Mean Percentage and Standard Deviation of Correct Responses Across Subjects Administered Five Tests of Action and Event Conceptual and Semantic Knowledge Retrieval

\begin{tabular}{llll}
\hline \multicolumn{1}{c}{ Test } & Form A & Form B \\
\hline Picture-word matching & $92 \pm 5$ & $93 \pm 6$ \\
Picture comparison & $82 \pm 9$ & $84 \pm 12$ \\
Word comparison & $84 \pm 12$ & $82 \pm 9$ \\
Picture attribute knowledge & $92 \pm 4$ & $91 \pm 5$ \\
Word attribute knowledge & $94 \pm 3$ & $91 \pm 7$ \\
\hline
\end{tabular}

edge related to actions and events, a capacity about which the neural correlates are virtually unknown. Digitized copies of all stimulus materials are available on request.

\section{COMMENT}

In developing a set of stimuli suitable for examining the retrieval of word forms denoting actions, we began by characterizing in detail a set of 280 stimuli depicting actions. Normative information regarding familiarity, image agreement, visual complexity, and verb frequency was also obtained for each of the 280 action and event stimuli. Exploration of the naming responses elicited by these stimuli demonstrated that they successfully elicited verbs that varied along a number of important dimensions, such as semantic category, transitivity, and inflectional form. Although overall name agreement was relatively high, variability in the responses elicited from different subjects was found. This variability appears to reflect features that are specific to the conceptual organization of verbs, and it would be inherent to any stimulus set which depicted a broad range of actions.

The sources of name disagreement that we found in our first experiment have implications for the development of any action-naming test. Specifically, although some of these sources of name disagreement can be reduced by the careful selection of stimulus items, in situations in which subjects freely choose the perspective from which to view a scene and the categorical level at which to describe an action, they cannot be completely eliminated. For this reason, for some items we developed standardized procedures to: (1) direct subjects' attention to a particular agent or object by pointing to a part of the picture and (2) encourage subjects to provide a second response through the utilization of specific prompts. The effectiveness of these administration procedures was demonstrated in a second experiment.

Finally, five tests were developed to assess the retrieval of conceptual knowledge for actions. These tests include most of the 280 items depicting actions and events, as well as the lexical forms for the target responses elicited by these stimuli.

These standardized stimuli and procedures, a comparable set of which has been previously unavailable, should facilitate research aimed at understanding the psychological and neural processes that underlie the acquisition and retrieval of knowledge for actions and action words.

\section{REFERENCES}

Basso, A., Capitani, E., \& Laincona, M. (1988). Progressive language impairment without dementia: A case with isolated category-specific semantic defect. Journal of Neurology. Neurosurgery, \& Psychiatry, 51, 1201-1207

Bates, E., Chen, S., Tzeng, O., Ll, P., \& OpIe, M. (1991). The noun-verb problem in Chinese aphasia. Brain \& Language, 41, 203-233.

Bayles, K. A., Tomoeda, C. K., \& Trosset, M.W. (1990). Naming and categorical knowledge in Alzheimer's disease: The process of semantic memory deterioration. Brain \& Language, 39, 498-510.

Behrend, D. A. (1990). The development of verb concepts: Children's 
use of verbs to label familiar and novel events. Child Development 61, 681-696.

Caramazza, A., \& Hillis, A. E. (1991). Lexical organization of nouns and verbs in the brain. Nature, 349, 788-790.

Chomsky, N. (1957). Syntactic structures. The Hague: Mouton.

Damasio, A. R., \& Damasio, H. (1993). Cortical systems underlying knowledge retrieval: Evidence from human lesion studies. In T. A Poggio \& D. A. Glaser (Eds.), Exploring brain functions: Models in neuroscience (pp. 223-248). New York: Wiley.

Damasio, A. R., Damasio, H., Tranel, D., \& Brandt, J. P. (1990). Neural regionalization of knowledge access: Preliminary evidence. Cold Spring Harbor Symposia on Quantitative Biology, 55, 1039-1047.

Damasio, A. R., \& Tranel, D. (1993). Nouns and verbs are retrieved with differently distributed neural systems. Proceedings of the National Academy of Sciences, 90, 4957-4960.

Damasio, H., Grabowski, T. J., Tranel, D., Hichwa, R. D., \& Damasio, A. R. (1996). A neural basis for lexical retrieval. Nature, 380, 499-505.

Daniele, A., Giustolisi, L., Silveri, M. C., Colosimo, C., \& GainOTTI, G. (1994). Evidence for a possible neuroanatomical basis for lexical processing of nouns and verbs. Neuropsychologia, 32, 1325-1341.

Farah, M. J., Meyer, M. M., \& McMullen, P. A. (1996). The living/nonliving dissociation is not an artifact: Giving an a priori implausible hypothesis a strong test. Cognitive Neuropsychology, 13, 137-154.

Fillmore, C. J. (1968). The case for case. In E. Bach \& R. J. Harms (Eds.), Universals in linguistic theory (pp. 1-88). New York: Holt, Rinehart \& Winston.

Fisher, C., Gleitman, H., Gleitman, L R. (1991). On the semantic content of subcategorization frames. Cognitive Psychology, 23, 331-391.

FRANCIS, W. M. \& KUČERA, H. (1982). Frequency analysis of English usage: Lexicon and grammar. Boston: Houghton Mifflin.

GERTMANN, D. J. (1990). Test of adolescent word finding. Allen, TX: DLM Teaching Resources.

GOOdGLASS, H., \& BAKER, E. (1976). Semantic field, naming, and auditory comprehension in aphasia. Brain \& Language, 3, 359-374.

Goodglass, H., Wingfield, A., Hyde, M. R., \& TheurKauf, J. C. (1986). Category specific dissociations in naming and recognition by aphasic patients. Cortex, 22, 87-102.

Grimshaw, J. (1990). Argument structure. Cambridge, MA: MIT Press

Gropen, J., Pinker, S., Hollander, M., \& Goldberg, R. (1991) Affectedness and direct objects: The role of lexical semantics in the acquisition of verb argument structure. Cognition, 41, 153-195.

GrUBER, J. (1976). Lexical structures in syntax and semantics. New York: North-Holland

Hart, J., Berndt, R. S., \& Caramazza, A. (1985). Category-specific naming deficit following cerebral infarction. Nature, 316, 439-440.

Hillis, A. E., \& Caramazza, A. (1991). Category-specific naming and comprehension impairment: A double dissociation. Brain, 114, 2081-2094.

JACKENDOFF, R. (1983). Semantics and cognition. Cambridge, MA: MIT Press.

JACKENDOFF, R. (1987). The status of thematic relations in linguistic theory. Linguistic Inquiry, 18, 369-411.

JACKENDOFF, R. (1990). Semantic structures. Cambridge, MA: MIT Press.

Klatzky, R. L., Pelleggrino, J., McCloskey, B. P., \& Lederman, S. J. (1993). Cognitive representations of functional interactions with objects. Memory \& Cognition, 21, 294-303.

Levin, B., \& Hovav, M. K. (1991). Wiping the slate clean: A lexical semantic exploration. Cognition, 41, 123-151.

LEVIN, B., \& RAPPAPORT, M. (1991). The lexical semantics of verbs of motion: The perspective from unaccusativity. In I. Roca (Ed.), Thematic structure: Its role in grammar. Berlin: Walter de Gruyter

Martin, A., \& FEDIO, P. (1983). Word production and comprehension in Alzheimer's disease: The breakdown of semantic knowledge. Brain \& Language, 19, 124-141.

Martin, A., Haxby, J. V., Lalonde, F. M., Wiggs, C. L., \& UngerLEIDER, L. G. (1995). Discrete cortical regions associated with knowledge of color and knowledge of action. Science, 270, 102-105

MCCARThY, R., \& Warrington, E. K. (1985). Category specificity in an agrammatic patient: The relative impairment of verb retrieval and comprehension. Neuropsychologia, 23, 709-727.
MCCARThy, R. A., \& WarRington, E. K. (1988). Evidence for modality-specific meaning systems in the brain. Nature, 334, 428-430.

Miceli, G., Silveri, M. C., Nocentini, U., \& Caramazza, A. (1988). Patterns of dissociations in comprehension and production of nouns and verbs. Aphasiology, 2, 351-358.

Miceli, G., Silveri, M. C., Villa, G. P., \& Caramazza, A. (1984). On the basis for the agrammatic's difficulty in producing main verbs. Cortex, 20, 207-220.

MilLeR, G. A. (1972). English verbs of motion: A case study in semantics and lexical memory. In A. W. Melton \& E. Martin (Eds.), Coding processes in human memory (pp. 334-372). Washington, DC: V. H. Winston \& Sons.

Miller, G. A., \& Fellbaum, C. (1991). Semantic networks of English. Cognition, 41, 197-229.

NAIGLES, L. G., \& KaKo, E. T. (1993). First contact in verb acquisition: Defining a role for syntax. Child Development, 64, 1665-87.

OBLeR, L., \& AlBERT, M. (1982). The action naming test. Boston: VA Medical Center.

Pietrini, V., Nertempi, P., Vaglia, A., Revelloo, H. G., Pinna, V., \& Ferro-Milona, F. (1988). Recovery from herpes simplex encephalitis: Selective impairment of specific semantic categories with neuroradiological correlation. Journal of Neurology, Neurosurgery, \& Psychiatry, 51, 1284-1293.

PINKER, S. (1989). Learnability and cognition: The acquisition of argument structure. Cambridge, MA: MIT Press.

SACCHEtT, C., \& Humphreys, G. W. (1992). Calling a squirrel a squirrel but a canoe a wigwam: A category-specific deficit for artefactual objects and body parts. Cognitive Neuropsychology, 9, 73-86.

SARTORI, G., \& JOB, R. (1988). The oyster with four legs: A neuropsychological study on the interaction of visual and semantic information. Cognitive Neuropsychology, 5, 105-132.

Sartori, G., Job, R., Miozzo, M., ZaGo, S., \& Marchiori, G. (1993) Category-specific form knowledge deficit in a patient with herpes simplex virus encephalitis. Journal of Clinical \& Experimental Neuropsychology, 15, 280-299.

Silveri, M. C., \& GainotTi, G. B. (1988). Interaction between vision and language in category specific semantic access impairment. Cognitive Neuropsychology, 5, 677-709.

Silveri, M. C., Giustolisi, L., \& Gainotti, G. (1991). Dissociation between knowledge of living and nonliving things in dementia of the Alzheimer type. Neurology, 41, 545-546.

SNODGRASs, J. G., \& VANDERWART, M. (1980). A standardized set of 260 pictures: Norms for name agreement, image agreement, familiarity, and visual complexity. Journal of Experimental Psychology. Human Learning \& Memory, 6, 247-269.

Tranel, D., Damasio, H., \& Damasio, A. R. (1997). On the neurology of naming. In H. Goodglass \& A. Wingfield (Eds.), Anomia: Neuroanatomical and cognitive correlates (pp. 67-92). New York: Academic Press.

WARRINGTON, E. K. (1975). The selective impairment of semantic memory. Quarterly Journal of Experimental Psychology, 27, 635-657.

Warrington, E. K., \& MCCARTHY, R. A. (1983). Category-specific access dysphasia. Brain, 106, 859-878.

Warrington, E. K., \& MCCARThy, R. A. (1987). Categories of knowledge: Further fractionations and an attempted integration. Brain, 110 , 1273-1296.

WarRington, E. K., \& MCCARThY, R. A. (1994). Multiple meaning systems in the brain: A case for visual semantics. Neuropsychologia, 32, 1465-1473.

WarRington, E. K., \& Shallice, T. (1984). Category specific semantic impairments. Brain, 107, 829-854

ZINGESER, L. B., \& BERNDT, R. S. (1988). Grammatical class and context effects in a case of pure anomia: Implications for models of language production. Cognitive Neuropsychology, 5, 473-516.

ZINGESER, L. B., \& BERNDT, R. S. (1990). Retrieval of nouns and verbs in agrammatism and anomia. Brain \& Language, 39, 14-32.

\section{NOTES}

1. For examples of category-specific naming defects for entities, see Basso. Capitani, Laiacona, 1988: A. R. Damasio, H. Damasio, Tranel, and Brandt, 1990; H. Damasio, Grabowski, Tranel, Hichwa, and A. R. 
Damasio, 1996; Farah, Meyer, and McMullen, in press; Goodglass, Wingfield, Hyde, and Theurkauf, 1986; Hart, Berndt, and Caramazza, 1985; Hillis and Caramazza, 1991; McCarthy and Warrington, 1988 Pietrini et al., 1988; Sacchett and Humphreys, 1992; Sartori and Job, 1988; Sartori, Job, Miozzo, Zago, and Marchiori, 1993; Silveri and Gainotti, 1988; Tranel, H. Damasio, and A. R. Damasio, 1997; Warrington and McCarthy, 1983, 1987, 1994; Warrington and Shallice, 1984.

2. For reports of subjects with action naming defects, see Bates, Chen, Tzeng, Li, and Opie, 1991; Caramazza and Hillis, 1991; Damasio and Tranel, 1993; Daniele, Giustolisi, Silveri, Colosimo, and Gainottti, 1994; McCarthy and Warrington, 1985; Miceli, Silveri, Nocen tini, and Caramazza, 1988; Miceli, Silveri, Villa, and Caramazza, 1984; Zingeser and Berndt, 1988, 1990. In general, researchers have relied on the analysis of individual patients, though some studies involving patient groups have been reported (Bates et al., I99 I; Miceli et al., 1984; Zingeser and Berndt, 1990), With a few exceptions (Damasio and Tranel, 1993; Daniele et al, 1994), neuroanatomical correlations be- tween lesion locations and naming defects were not made. In only a few cases (Bates et al., 1991; McCarthy and Warrington, 1985; Miceli et al., 1988) was the retrieval of both lexical and conceptual knowledge for actions examined

3. Historically the stimuli used in picture-naming studies (in both normal and patient populations) have relied on single black and white line drawings of objects, most commonly those developed by Snodgrass and Vanderwart (1980). The use of color pictures and picture pairs in the present study may thus raise concerns about how well performance can be compared across such different stimulus sets. Although this important issue should be considered in any direct comparison of performance between the two stimulus sets, such a comparison was not our goal. Rather, our intention was to develop a set of stimuli that most clearly depicted a broad range of actions. However, as noted in the Results and Discussion section of Experiment $I_{1}$ in some cases striking similarities were found between the results in the present study and those reported by Snodgrass and Vanderwart, despite differences in the nature of the stimuli.

\section{APPENDIX A \\ Responses to Each Item Presented in Experiment 1}

Note: The predominant target response is listed for each item (nondominant responses indicated with asterisks), along with all other responses to the item. The number of subjects (out of 64) who produced each response is indicated after each word, to give a total of 64 responses produced for each item. Items that elicit gerundial (-ing) forms are listed first, followed by items that elicit past tense forms.

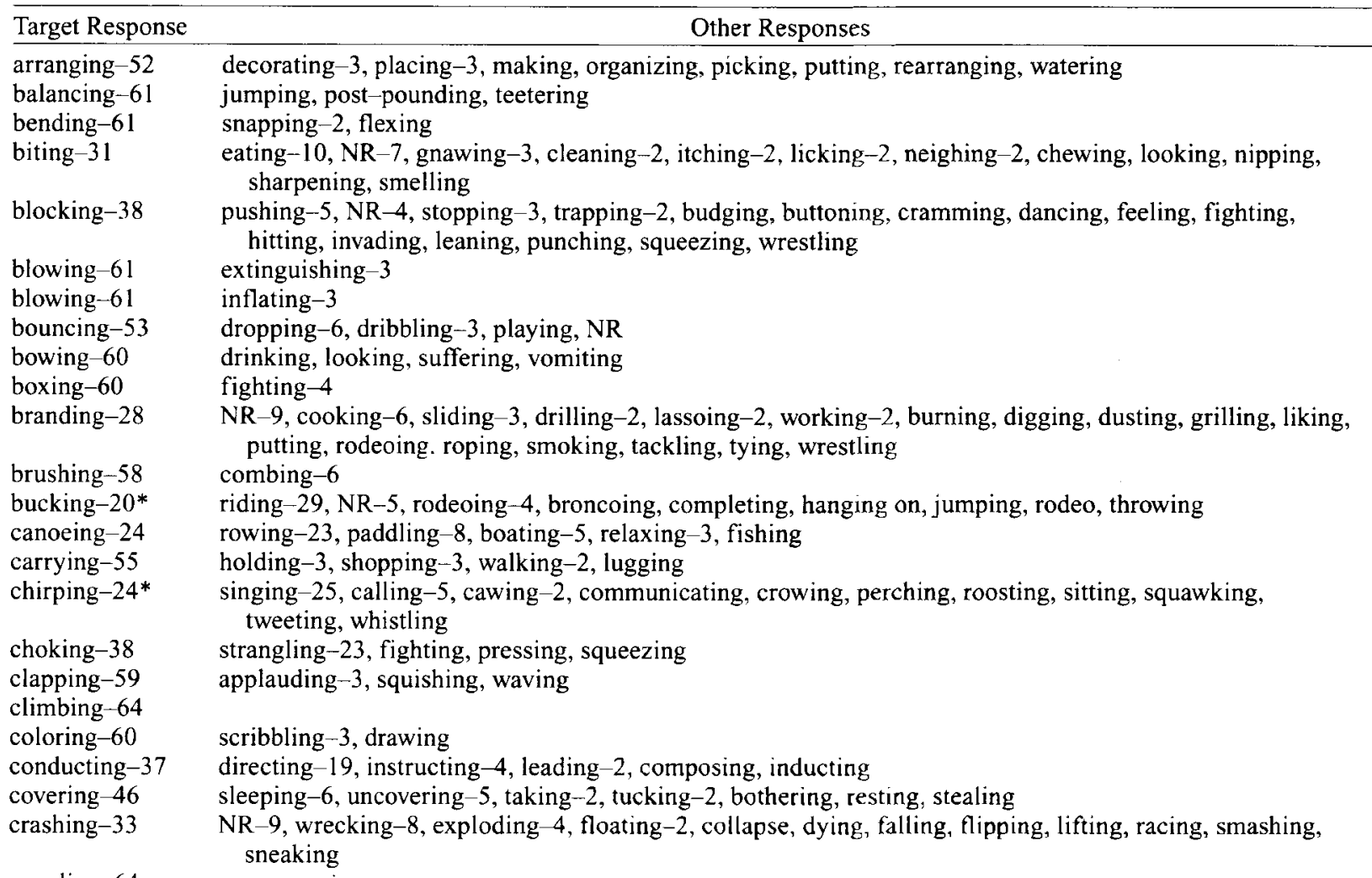

crawling-64

crumpling-52

crushing- 41

curling-62

curtsying-37

cutting 64

dealing-56

dialing -58

directing-53

crushing-3, crinkling-2, balling, crumple, folding, NR, scrumpling, wadding, wrinkling smashing-19, squashing-2, leaning, pushing

brushing, drying

bowing-18, dancing-7, curtsy, kneeling

playing-3, distributing -2 , gambling, placing, sorting

calling- 3 , pushing- 2 , pressing

signaling-2, conducting, controlling, crossing, interfering, motioning, NR, patrolling, stopping, walking 
APPENDIX A (Continued)

\begin{tabular}{|c|c|}
\hline Target Response & Other Responses \\
\hline diving-28 & $\begin{array}{l}\text { flying-10, swooping-10, fishing }-4 \text {, catching-2, hunting }-2 \text {, landing-2, attacking, dipping, eating, feeding, } \\
\text { gliding, soaring }\end{array}$ \\
\hline diving-57 & tucking-3, piking-2, falling, flexing \\
\hline dragging-57 & carrying -4 , pulling -2 , holding \\
\hline dripping-55 & leaking -2 , washing -2 , draining, existing, $N R$, running, shining \\
\hline ducking-18 & $\begin{array}{l}\text { dodging }-12 \text {, hitting }-9 \text {, avoiding }-4 \text {, blocking }-4 \text {, missing }-3 \text {, guarding }-2 \text {, moving }-2 \text {, protecting }-2 \text {, bouncing, } \\
\text { flinching, hit, reacting, shielding, throwing, tricking, NR }\end{array}$ \\
\hline dunking-33 & dipping -25 , soaking -3 , removing, saturating, squeezing \\
\hline dusting-23* & cleaning-24, wiping-17 \\
\hline eating-59 & tasking-2, anticipating, hungry, snacking \\
\hline erasing -63 & cleaning \\
\hline erupting -25 & exploding $19, N R-12$, smoking -4 , explosion, floating, polluting, swimming \\
\hline fainting -49 & falling -7 , catching -5 , collapsing, leaning, sick \\
\hline feeding-52 & eating- 3 , playing -2 , teething- 2 , grasping, NR, plunging, squeezing, sucking \\
\hline fencing -46 & fighting-9, jousting -5 , jabbing, playing, stabbing, swording \\
\hline fighting -41 & $\begin{array}{l}\text { kicking-6, playing }-4 \text {, attacking-2, bucking-2, rearing-2, challenging, frolicking, funning, horseplay, } \\
\text { jumping, mating, popping }\end{array}$ \\
\hline fighting -44 & attacking-5, biting -5 , snarling -3 , brawling, chasing, growling, $N R$, running, scaring, smiling \\
\hline fishing-63 & casting \\
\hline flexing-60 & bulging, hot-dogging, making, offering \\
\hline flipping-33 & $\begin{array}{l}\text { tossing-9, hitchhiking }-4 \text {, signaling-3, approving-2, gesturing-2, NR-2, accepting, agreeing, extending, } \\
\text { gesture, giving thumbs-up, hitching, OK'ing, signing, thumbing }\end{array}$ \\
\hline flowing-34 & $\begin{array}{l}\text { erupting-10, burning-6, running-3, melting-2, blazing, exploding, lava, NR, oozing, overflowing, pouring, } \\
\text { smoldering, stormy }\end{array}$ \\
\hline flying -63 & landing \\
\hline folding-61 & wrapping-2, covering \\
\hline following-1 $1^{*}$ & swimming -41 , leading -4 , floating -3 , gliding, teaching, wading, washing \\
\hline frowning-20 & $\begin{array}{l}\text { looking- }-6 \text {, thinking }-6 \text {, confusing }-5, \mathrm{NR}-3 \text {, questioning- }-3 \text {, wondering- }-3 \text {, grimacing- } 2 \text {, scowling-2, } \\
\text { staring-2, worrying-2, confused, disbelief, disbelieving, doubting, glaring, pouting, sad, smirking, } \\
\text { squinting, wincing }\end{array}$ \\
\hline galloping -40 & running-18, trotting -3 , cantering -2 , highstepping \\
\hline gesturing-6* & $\begin{array}{l}\text { speaking-21, lecturing-11, teaching- } 8 \text {, talking- } 4 \text {, explaining-3, instructing-3, answering, conducting, } \\
\text { discussing, motioning, oath giving, preaching, presenting, sitting }\end{array}$ \\
\hline grabbing-22* & pulling -29 , tugging-11, examining, plucking \\
\hline grating-43 & shredding-16, shaving-2, slicing-2, peeling \\
\hline grazing -40 & eating-22, bending, chewing \\
\hline hammering -40 & nailing-18, pounding-6 \\
\hline hanging -63 & grabbing \\
\hline harvesting-26 & $\begin{array}{l}\text { plowing }-13 \text {, combining- }-8 \text {, farming- }-8 \text {, unloading }-2 \text {, cutting, husking, picking, planting, pouring, } \\
\text { separating, working }\end{array}$ \\
\hline $\begin{array}{l}\text { hatching }-41 \\
\text { herding-11* }\end{array}$ & $\begin{array}{l}\text { NR-5, cracking }-4 \text {, breaking-3, emerging-2, opening-2, peeling- } 2 \text {, being born, birth, egg, living, pushing } \\
\text { running-18, galloping- } 13 \text {, rounding (up)-8, gathering-3, riding-3, chasing- } 2 \text {, corralling-2, grazing, } \\
\text { harassing, horsing, snowing }\end{array}$ \\
\hline hiding 46 & $\begin{array}{l}\text { looking-4, peeking-3, talking-2, chatting, conversing, gardening, greeting, observing, planting, searching, } \\
\text { seeking, swaying }\end{array}$ \\
\hline hiking-55 & climbing-4, backpacking-2, discovering, picture, walking \\
\hline hobbling $-3^{*}$ & tying-44, NR-5, untying 4 , binding, fixing, handcuffing, knotting, planting, potting, roping, untangling \\
\hline holding-34 & carrying-24, standing- -4 , waiting-2 \\
\hline holding-59 & grasping-2, crossing, kissing, NR \\
\hline hugging-31 & celebrating -26 , rejoicing -5 , winning -2 \\
\hline hurdling-52 & jumping-8, leaping- -3 , running \\
\hline $\begin{array}{l}\text { interviewing-18* } \\
\text { juggling-64 }\end{array}$ & speaking- 30 , talking -8 , singing- 3 , holding- 2 , amplifying, auditioning, performing \\
\hline kicking-62 & dribbling, kick \\
\hline kissing-61 & harassing, loving, pecking \\
\hline kneeling-63 & bending \\
\hline knitting-50 & crocheting -4 , sewing -4 , stitching -2 , darning, mending, needle, needlepointing \\
\hline knocking-59 & communicating, directing, measuring, screeching, writing \\
\hline laminating-35 & $\begin{array}{l}\text { sticking-6, sealing }-5 \text {, taping }-5 \text {, holding }-4 \text {, covering }-2, N R-2 \text {, buttoning, checking, driving, positioning, } \\
\text { shellacking }\end{array}$ \\
\hline laugh & tickling- 62 , playing-2 \\
\hline
\end{tabular}


APPENDIX A (Continued)

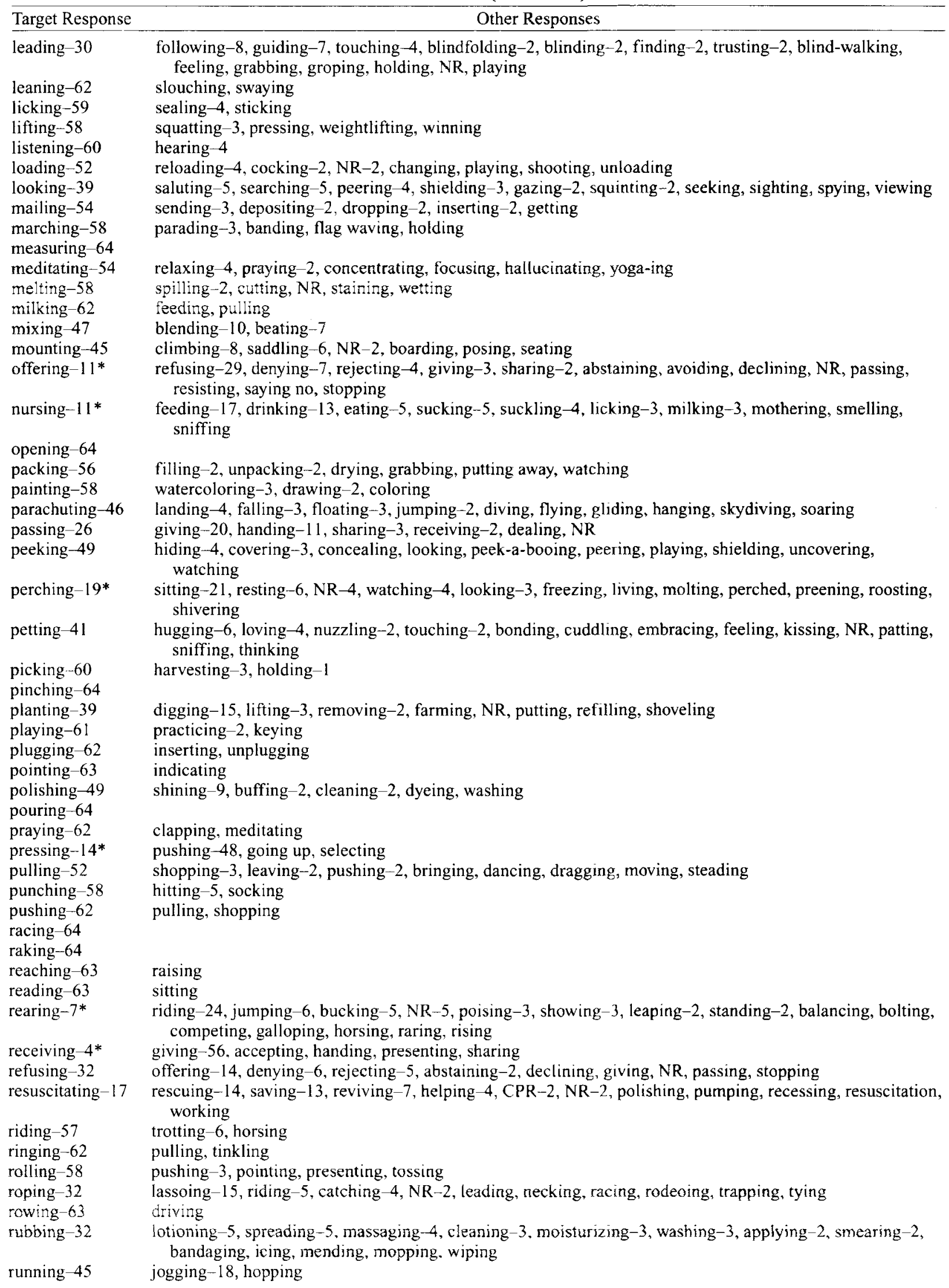


APPENDIX A (Continued)

\begin{tabular}{|c|c|}
\hline Target Response & Other Responses \\
\hline sailing-61 & boating-2, sailboat \\
\hline saluting-60 & looking-4 \\
\hline sawing-62 & cutting-2 \\
\hline scratching-58 & itching-6 \\
\hline screwing-57 & fixing-3, turning-2, dropping, punching \\
\hline scrubbing-55 & cleaning-5, rubbing, scraping, washing, wiping \\
\hline sewing-46 & mending -7 , darning -4 , knitting -2 , stitching- 2 , folding, repairing, unstitching \\
\hline shaking-54 & greeting-5, meeting -4 , agreeing \\
\hline sharing-26* & eating-34, forking, indulging, piecing, sculpting \\
\hline shearing-39 & $\begin{array}{l}\text { shaving }-7 \text {, NR-5, stuffing-3, arising, bathing, binding, cleaning, cutting, dewooling, hanging, trimming, } \\
\text { unstuffing, wooling }\end{array}$ \\
\hline shooting-53 & hunting-3, aiming $-2, \mathrm{NR}-2$, catching, diving, looking, pooling \\
\hline shoving-12* & pushing-52 \\
\hline shrugging-21 & $\begin{array}{l}\text { frowning-13, looking-6, NR-6, smiling-6, grinning-3, doubting-2, questioning-2, smirking-2, agreeing, } \\
\text { unknowing, watching }\end{array}$ \\
\hline shuffling- 62 & mixing, stamping \\
\hline signing- 45 & writing -13 , paying -2 , spending -2 , dating, picking \\
\hline singing-63 & wailing \\
\hline sitting-58 & waiting-2, focusing, listening, relaxing, watching \\
\hline skating-55 & ice-skating -8 , walking \\
\hline skiing-64 & \\
\hline slapping-57 & smacking-4, hitting-3 \\
\hline sledding-55 & screaming -4 , sliding -3 , riding, sailing \\
\hline sleeping -60 & napping-2, hibernating, snoozing \\
\hline slicing-21* & cutting-36, peeling -4 , paring -2 , coring \\
\hline sliding-41 & falling-11, leaning-2, NR-2, sticking-2, dropping, hanging, levitating, slanting, slipping, tipping \\
\hline sliding-64 & \\
\hline slouching-21 & $\begin{array}{l}\text { sitting-19, relaxing-8, watching-6, resting- }-3 \text {, arching, boring, daydreaming, leaning, listening, lounging, } \\
\text { slumping }\end{array}$ \\
\hline smelling-62 & ( \\
\hline smiling-64 & \\
\hline smoking-60 & daydreaming, holding, teaching, thinking \\
\hline sneezing -57 & eating-3, coughing, moaning, sneeze, spitting \\
\hline speaking-23 & $\begin{array}{l}\text { lecturing }-16 \text {, teaching }-9 \text {, talking }-5 \text {, orating }-2 \text {, preaching }-2 \text {, bowing, conducting, demonstrating, } \\
\text { explaining, instructing, learning, presenting }\end{array}$ \\
\hline spilling -40 & leaking-18, spilled-2, dripping, pouring, spill, spilt \\
\hline spilling-59 & flowing, spill, spilled, spilt, spreading \\
\hline spinning-27 & weaving-13, NR-11, sewing-5, making- 2 , knitting, looking, standing, turning, working, yarning \\
\hline spinning-57 & playing -4 , point, turning, twirling \\
\hline spraying-53 & squirting-10, spritzing \\
\hline sprinkling-41 & $\begin{array}{l}\text { baking }-7 \text {, sugaring }-4 \text {, powdering-3, decorating-2, adding, applying, cooking, icing, NR, seasoning, } \\
\text { topping }\end{array}$ \\
\hline squatting-54 & crouching -5 , kneeling -3 , bending- 2 \\
\hline squeezing-62 & juicing, squishing \\
\hline squinting 40 & $\begin{array}{l}\text { glaring }-6 \text {, scowling }-6, \text { NR }-2 \text {, smirking }-2 \text {, sneering-2, closing, contemplating, frowning, sleeping, smiling, } \\
\text { wincing }\end{array}$ \\
\hline standing -60 & frowning, looking, staring, wondering \\
\hline sticking -32 & $\begin{array}{l}\text { clinging- } 16 \text {, holding }-4 \text {, attracting }-2 \text {, experimenting }-2, N R-2 \text {, connecting, electricity, filling, playing, } \\
\text { showing static, static }\end{array}$ \\
\hline stirring-61 & mixing -3 \\
\hline straddling -45 & standing -8 , crossing $-4, N R-3$, angered, entering, hurdling, protecting \\
\hline stretching-46 & reaching-13, hanging-2, extending, NR, raising \\
\hline surfing-63 & surfboarding \\
\hline sweeping-60 & mopping-3, cleaning \\
\hline swimming-61 & breathing, racing \\
\hline swinging-64 & \\
\hline tickling -58 & harassing-2, giggling, laughing, playing, scratching \\
\hline tiptoeing-43 & sneaking-8, dancing $-3, \mathrm{NR}-3$, shushing- 2 , being quiet, crecping, quieting, quietly, sshhing, \\
\hline tracing -49 & drawing-13, outlining-2 \\
\hline trading-56 & dealing-3, exchanging -2 , looking, playing, showing \\
\hline trimming $-12 *$ & cutting- 34 , clipping- 6 , pruning- 6 , fixing-2, building, grasping, NR, snipping \\
\hline tucking-54 & buttoning -5 , dressing -2 , unbuttoning -2 , feeling \\
\hline
\end{tabular}


APPENDIX A (Continued)

\begin{tabular}{|c|c|}
\hline Target Response & Other Responses \\
\hline turning-58 & steering 4 , driving, twisting \\
\hline twirling- 60 & cheerleading, spinning, twirled, waving \\
\hline twisting-59 & wringing-2, folding, rolling, squeezing \\
\hline typing-63 & reading \\
\hline unlocking-32 & locking-19, opening- 5 , turning- 5 , inserting $-2, N R$ \\
\hline vacuuming-59 & walking-2, cleaning, NR, sucking \\
\hline walking-61 & strolling-2, striding \\
\hline washing- 57 & rinsing- 4 , cleaning, cleansing, NR \\
\hline watching-58 & sitting -3 , relaxing, vegetating, viewing \\
\hline watering-55 & pouring- 6 , nourishing, NR, sculpturing \\
\hline waving- -61 & smiling-3 \\
\hline weaving-19 & $\begin{array}{l}\text { NR-17, cutting-3, measuring-3, glowing-2, making-3, working-2, boating, grating, knitting, leveling, } \\
\text { looking, looming, picking up, reaching, sawing, stretching, tightening, tying, welding, wrapping, writing }\end{array}$ \\
\hline \multicolumn{2}{|r|}{ 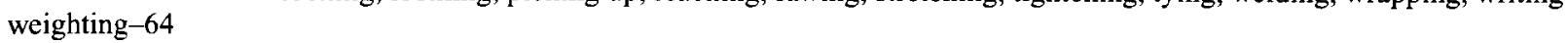 } \\
\hline whispering-57 & telling-5, eating, talking \\
\hline whittling- 25 & carving -15 , shaving -11 , peeling -3 , cutting $-2, N R-2$, scraping- 2 , chiseling, filing, sharpening, shellacking \\
\hline winding- 45 & twisting -5 , turning -4 , playing- -3 , fixing -2 , assembling, gluing, holding, loading, spinning \\
\hline winking-58 & blinking $-3, N R$, smiling, squinting \\
\hline wiping-34 & crying- 13 , sniffling 9 , blowing-5, clotting, sneezing, sobbing \\
\hline wrestling 61 & fighting-2, grappling \\
\hline yawning 47 & roaring-15, calling, roar \\
\hline yelling-44 & shouting -14 , hollering -3 , screaming -2 , cheering \\
\hline absorbed-26 & soaked (up) -17 , cleaned -8 , wiped (up) -8 , dispersed, mopped, NR, spread, touched \\
\hline addressed-54 & NR-2, signed- -2 , switched -2 , erased, finished, posted, written \\
\hline assembled-33 & $\begin{array}{l}\text { fixed-12, NR-5, put together }-3 \text {, constructed }-2 \text {, reassembled }-2 \text {, repaired- } 2 \text {, closed, combined, compiled, } \\
\text { disassembled, placed }\end{array}$ \\
\hline baked-53 & cooked-10, fried \\
\hline broken-36 & broke-16, shattered-12 \\
\hline buried-31 & covered-17, filled $-9, N R-2$, smoothed -2 , dried, evened, exterminated \\
\hline carved-63 & cut \\
\hline caught -55 & catched -3 , tossed -2 , catch, catching, pitched, received \\
\hline chewed-62 & compressed, spit \\
\hline chipped-53 & cracked -6 , broken -4 , broke \\
\hline chopped-36 & diced-19, cut -8, sliced \\
\hline closed-62 & shut-2 \\
\hline coiled-23 & rolled -19 , curled -6 , wound -5, winded -4 , raveled -2 , circled, gathered, spun, swirled, twizzled \\
\hline connected-41 & joined -5 , attached $-4, N R-3$, fixed -2 , twisted -2 , wired- -2 , combined, fastened, fused, spliced, tied \\
\hline cracked-51 & broke -7 , broken- 4 , fractured, split \\
\hline crumbled--34 & broken-13, eaten -5 . broke-3, NR-3, bitten, chewed, crumb, crumbed, crushed, eaten \\
\hline cut -28 & ripped-14, torn-14, tear- 2 , tore-2, divided, sliced, slitted, split \\
\hline developed-56 & exposed-3, processed- 2 , lightened, NR, removed \\
\hline dissolved -27 & mixed -19 , melted -10 , combined- 5 , added, NR, stirred \\
\hline drank-50 & drunk-4, emptied-3, empty-2, finish-2, gone, guzzled, NR \\
\hline drawn-42 & drew -14 , draw -3 , created-2, illustrated, NR, painted \\
\hline dressed-60 & clothed-2, dress, undressed \\
\hline dropped-61 & drop, fluttered, released \\
\hline $\operatorname{dug}-46$ & $\begin{array}{l}\text { NR-3, uncovered-3, digged-2, shoveled-2, dropped, emptied, hole, imprinted, stepped, unburied, undug, } \\
\text { unearthed }\end{array}$ \\
\hline emptied-58 & empty-4, popped, removed \\
\hline enlarged-52 & centered -4 , bigger -2 , brightened, broadened, drawn, expanded, NR, swam \\
\hline extinguished- -31 & $\begin{array}{l}\text { blown (out)-13, NR-5, unlit-3, blew-2, burned-2, put out-2, dampened, flickered, out, snuffed, stopped, } \\
\text { unlighted }\end{array}$ \\
\hline fell-36 & fallen-17, dropped-6, landed-2, fall, fix, NR \\
\hline filled-62 & fill, refilled \\
\hline fixed -50 & repaired-11, assembled, glued, mended \\
\hline framed-64 & \\
\hline frayed-30 & $\begin{array}{l}\text { shredded }-6, \mathrm{NR}-3 \text {, ripped }-3 \text {, tattered }-3 \text {, torn }-3 \text {, unraveled }-3 \text {, unravel- }-2 \text {, cut, fradded, fringed, raveled, } \\
\text { smoothed, straggled, strewned, tore, unhemmed, worn }\end{array}$ \\
\hline fried-28* & cooked- 33 , baked -2 , burned \\
\hline frozen -31 & $\begin{array}{l}\text { froze-13, broken }-4, \mathrm{NR}-3 \text {, emptied }-2 \text {, freezed }-2 \text {, shattered }-2, \text { spilled }-2 \text {, empty, poured, removed, } \\
\text { smashed, transformed }\end{array}$ \\
\hline gave $-5 *$ & received -35 , given -11 , accepted -7 , exchanged -2 , handed, kept, NR, present \\
\hline
\end{tabular}


APPENDIX A (Continued)

\begin{tabular}{|c|c|}
\hline Target Response & Other Responses \\
\hline grew-14* & planted-17, grown-13, sprouted-12, growing-2, bloomed, growed, growth, NR, plant, seeded \\
\hline ground-34 & grounded -10 , grinded -7 , crushed -4 , smashed -3 , grind, mashed, minced, pounded, pulverized, smash \\
\hline ironed-52 & pressed- 4 , smoothed -2 , folded, NR, reversed, smooth, straightened, unwrinkled \\
\hline jumped-52 & hopped -4 , jump -4 , jumping, leaped, leapt, levitated \\
\hline labeled-48 & filed-5, named-3, titled-2, applied, identified, stamped, sticker, tagged, written \\
\hline lifted-52 & picked (up) -4, lift -3 , carried, hauled, held, raised, struggled, planted \\
\hline lit -45 & lighted -10 , light -5 , burned, ignited, illuminated, NR \\
\hline lowered-26 & $\begin{array}{l}\text { NR-9, answered-6, dropped-5, waved }-4 \text {, raised- } 2 \text {, relaxed- }-2 \text {, called on, calmed, done, put down, } \\
\text { questioned, released, resigned, said good-bye, silenced, silent }\end{array}$ \\
\hline mixed-51 & combined-11, stirred-2 \\
\hline nailed 49 & hammered -6 , pounded -4 , erased -2 , drilled, inserted, NR \\
\hline peeled-56 & opened-3, molded, NR, split, spoiled, unpeeled \\
\hline poked -41 & punctured -10 , punched -3 , pushed -2 , broke, damaged, inserted, NR, penetrated, pierced, ripped, stabbed \\
\hline popped -60 & burst, busted, exploded, extracted \\
\hline removed-56 & NR-2, extracted, pulled, released, taken off, uncovered, unmasked \\
\hline ripped -42 & torn-16, blued, cut, dyed, tear, teared, tore \\
\hline separated -47 & sorted-11, folded-2, assorted, rearranged, stacked, washed \\
\hline sharpened-62 & sharped, sharpen \\
\hline shredded-59 & shred-2, cut, sheared, torn \\
\hline smeared-43 & smudged-16, NR-2, magnetized, moved, used \\
\hline snapped--58 & snap-2, clicked, moved, NR, separated \\
\hline spit-45 & spitted-7, NR-3, spat-3, removed-2, expelled, found, observed, regurgitated \\
\hline spread-59 & spreaded-3, flattened, smeared \\
\hline stacked-57 & piled -3 , organized -2 , arranged, NR \\
\hline stained-56 & soiled-2, spilled-2, removed, spilt, spotted, washed \\
\hline straightened-36 & $\begin{array}{l}\text { NR-6, fixed- }-5 \text {, evened- }-3 \text {, pressed- } 2 \text {, pulled- } 2 \text {, straighten- } 2 \text {, enlarged, even, folded, ironed, laid, pleated, } \\
\text { shifted, smoothed }\end{array}$ \\
\hline switched-42 & $\begin{array}{l}\text { reversed-5, rearranged }-4, \text { NR }-3 \text {, moved }-2 \text {, changed, exchanged, flipped, nothing, played, redealt, switch, } \\
\text { traded }\end{array}$ \\
\hline swung 40 & hit -7 , swang -5 , swing -5 , backhanded, batted, differentiated, hitting, NR, reached, waved \\
\hline threaded -48 & thread-9, NR-2, inserted, needled, sewed, sewn, unraveled \\
\hline thrown-27 & threw -19 , tossed-13, throwed- 2 , passed, pitched, throw \\
\hline tied-59 & laced-3, released, tie \\
\hline toasted-61 & burnt, cooked, fried \\
\hline turned-55 & reversed -4 , rotated -2 , backwards, moved, NR \\
\hline wrapped-63 & wrap \\
\hline wrinkled-57 & crumpled -2 , ironed, $N R$, reversed, ruffled, rumpled \\
\hline written (on)-36 & wrote- -20, NR -3 , used-2, dirtied, smeared, writtened \\
\hline
\end{tabular}

\section{APPENDIX B}

Normative Statistics From Experiment 1

Note: Values for name agreement ( $H$ statistic and \% agreement), familiarity, visual complexity, image agreement, and word frequency (Francis \& Kučera, 1982) for the 280 items constituting a standard test of action and event naming. For those items in which the dominant response is not a target response, the dominant response and image agreement values for this word are listed in parentheses. Items are listed in the same order as for Appendix A.

\begin{tabular}{|c|c|c|c|c|c|c|c|c|c|}
\hline \multirow{2}{*}{$\begin{array}{c}\text { Target Response } \\
\text { (Dominant Response) }\end{array}$} & \multicolumn{2}{|c|}{$\begin{array}{c}\text { Name } \\
\text { Agreement }\end{array}$} & \multicolumn{2}{|c|}{ Familiarity } & \multicolumn{2}{|c|}{$\begin{array}{c}\text { Visual } \\
\text { Complexity }\end{array}$} & \multicolumn{2}{|c|}{ Image Agreement } & \multirow{2}{*}{$\begin{array}{c}\text { Word } \\
\text { Frequency }\end{array}$} \\
\hline & $H$ & $\%$ & $M$ & $S D$ & $M$ & $S D$ & $M$ & $S D$ & \\
\hline arranging & 1.22 & 81 & 2.88 & 1.20 & 2.63 & 0.59 & 3.75 & 1.10 & 71 \\
\hline balancing & 0.35 & 95 & 2.55 & 1.24 & 2.88 & 1.02 & 4.03 & 1.10 & 32 \\
\hline bending & 0.32 & 95 & 2.25 & 1.24 & 1.75 & 0.78 & 3.50 & 1.48 & 50 \\
\hline biting & 2.58 & 48 & 1.88 & 1.24 & 3.68 & 1.05 & 3.50 & 1.30 & 26 \\
\hline blocking & 2.47 & 59 & 2.25 & 1.10 & 3.05 & 0.81 & 3.45 & 1.41 & 20 \\
\hline blowing & 0.27 & 95 & 3.33 & 1.12 & 1.98 & 0.83 & 3.73 & 1.22 & 52 \\
\hline blowing & 0.27 & 95 & 3.08 & 1.23 & 2.08 & 0.57 & 3.80 & 1.40 & 52 \\
\hline bouncing & 0.94 & 83 & 3.15 & 1.17 & 1.80 & 0.69 & 3.98 & 1.27 & 28 \\
\hline bowing & 0.46 & 94 & 2.70 & 1.24 & 1.58 & 0.64 & 4.70 & 0.65 & 13 \\
\hline boxing & 0.34 & 94 & 2.68 & 1.58 & 4.00 & 0.93 & 4.95 & 0.22 & 4 \\
\hline branding & 3.04 & 44 & 1.88 & 1.20 & 4.40 & 1.01 & 4.50 & 1.18 & 3 \\
\hline
\end{tabular}


APPENDIX B (Continued)

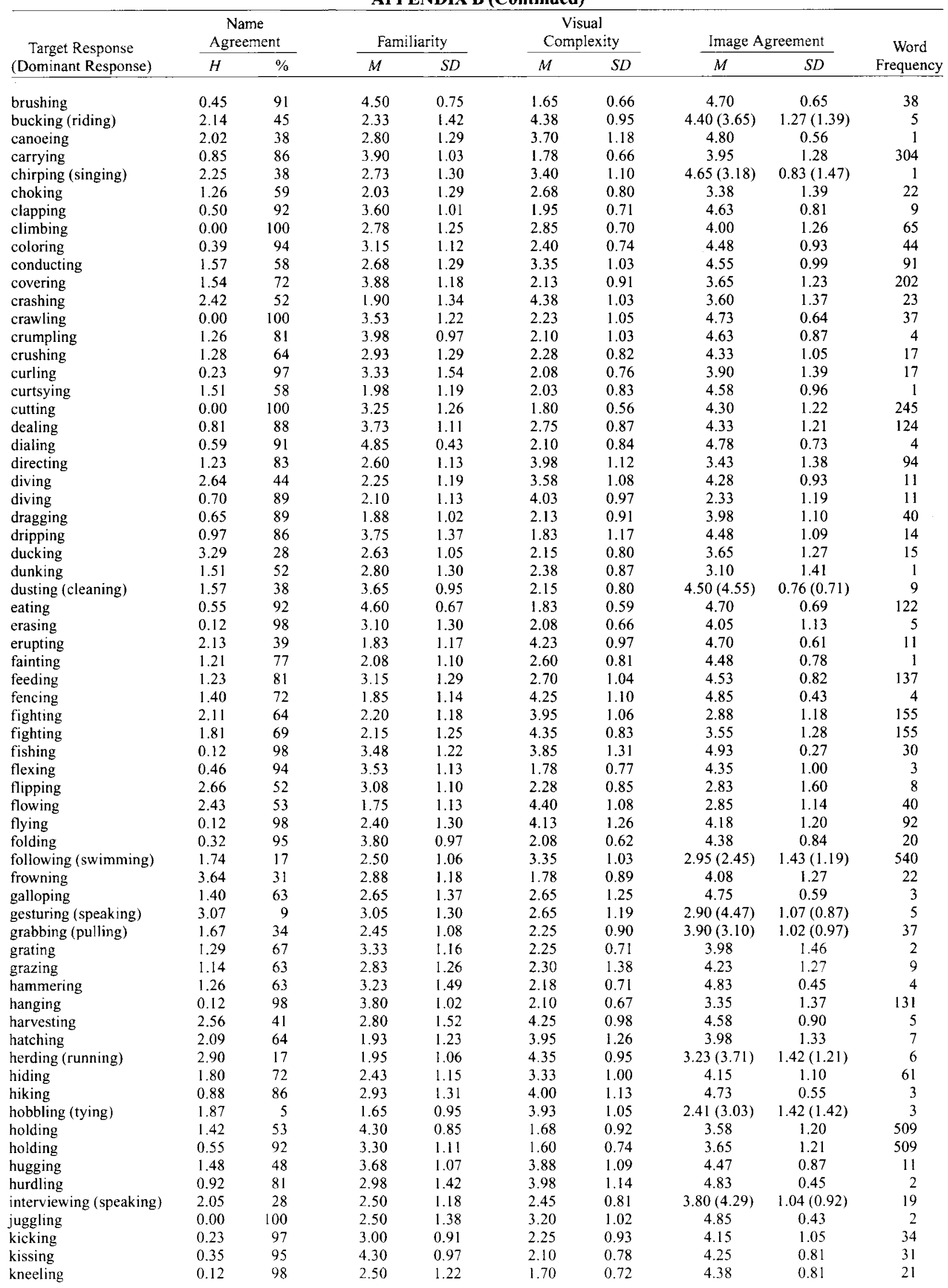


APPENDIX B (Continued)

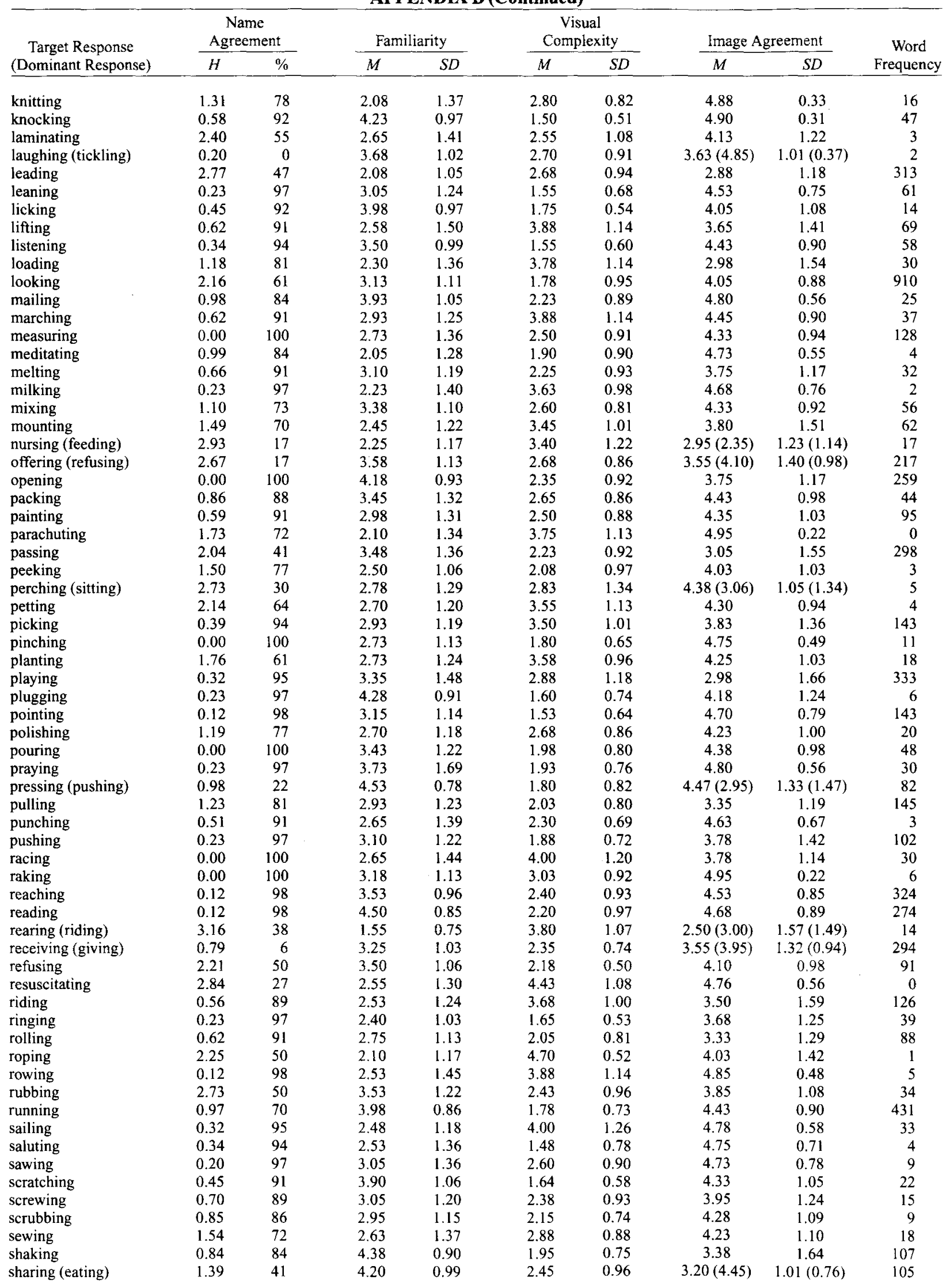


APPENDIX B (Continued)

\begin{tabular}{|c|c|c|c|c|c|c|c|c|c|}
\hline \multirow{2}{*}{$\begin{array}{c}\text { Target Response } \\
\text { (Dominant Response) }\end{array}$} & \multicolumn{2}{|c|}{$\begin{array}{c}\text { Name } \\
\text { Agreement }\end{array}$} & \multicolumn{2}{|c|}{ Familiarity } & \multicolumn{2}{|c|}{$\begin{array}{c}\text { Visual } \\
\text { Complexity }\end{array}$} & \multicolumn{2}{|c|}{ Image Agreement } & \multirow{2}{*}{$\begin{array}{c}\text { Word } \\
\text { Frequency }\end{array}$} \\
\hline & $H$ & $\%$ & $M$ & $S D$ & $M$ & $S D$ & $M$ & $S D$ & \\
\hline shearing & 2.22 & 61 & 1.73 & 1.18 & 4.30 & 0.97 & 2.85 & 1.73 & 6 \\
\hline shooting & 1.12 & 83 & 2.40 & 1.45 & 3.68 & 1.12 & 4.30 & 0.97 & 117 \\
\hline shoving (pushing) & 0.70 & 19 & 2.78 & 1.10 & 2.40 & 0.71 & $4.53(4.05)$ & $0.90(1.23)$ & 16 \\
\hline shrugging & 2.91 & 33 & 3.03 & 1.17 & 1.43 & 0.71 & 4.10 & 1.48 & 18 \\
\hline shuffling & 0.23 & 97 & 3.90 & 1.06 & 2.23 & 0.58 & 4.68 & 0.83 & 6 \\
\hline signing & 1.32 & 70 & 4.33 & 0.97 & 2.43 & 1.26 & 4.50 & 1.01 & 62 \\
\hline singing & 0.12 & 98 & 3.55 & 1.28 & 2.30 & 0.91 & 4.43 & 1.06 & 120 \\
\hline sitting & 0.66 & 91 & 3.95 & 1.20 & 1.45 & 0.75 & 4.73 & 0.60 & 314 \\
\hline skating & 0.66 & 86 & 2.75 & 1.37 & 3.83 & 1.08 & 4.38 & 0.98 & 3 \\
\hline skiing & 0.00 & 100 & 3.25 & 1.50 & 3.93 & 1.19 & 4.88 & 0.52 & 5 \\
\hline slapping & 0.61 & 89 & 2.73 & 1.41 & 2.28 & 0.78 & 4.50 & 0.85 & 17 \\
\hline sledding & 0.83 & 86 & 3.80 & 1.02 & 3.18 & 1.34 & 4.73 & 0.75 & 0 \\
\hline sleeping & 0.43 & 94 & 4.70 & 0.76 & 1.43 & 0.64 & 4.70 & 0.82 & 97 \\
\hline slicing (cutting) & 1.49 & 33 & 3.95 & 0.99 & 2.33 & 0.86 & $4.50(4.24)$ & $0.75(1.09)$ & 7 \\
\hline sliding & 1.88 & 64 & 3.30 & 1.09 & 2.80 & 1.14 & 3.83 & 1.32 & 43 \\
\hline sliding & 0.00 & 100 & 1.78 & 1.17 & 2.88 & 1.28 & 2.43 & 1.22 & 43 \\
\hline slouching & 2.61 & 33 & 3.63 & 1.51 & 1.68 & 0.86 & 4.40 & 1.13 & 1 \\
\hline smelling & 0.20 & 97 & 3.60 & 1.17 & 1.80 & 0.65 & 4.68 & 0.57 & 43 \\
\hline smiling & 0.00 & 100 & 4.15 & 1.00 & 1.25 & 0.54 & 4.88 & 0.40 & 122 \\
\hline smoking & 0.46 & 94 & 3.63 & 1.51 & 1.80 & 0.76 & 4.53 & 0.99 & 26 \\
\hline sneezing & 0.73 & 89 & 4.20 & 0.88 & 2.15 & 1.10 & 4.53 & 0.88 & 3 \\
\hline speaking & 2.69 & 36 & 3.15 & 1.29 & 2.53 & 0.93 & 4.47 & 0.87 & 274 \\
\hline spilling & 1.47 & 63 & 3.15 & 1.00 & 1.48 & 0.68 & 4.18 & 1.08 & 9 \\
\hline spilling & 0.58 & 92 & 3.50 & 1.06 & 1.68 & 0.62 & 4.58 & 0.81 & 9 \\
\hline spinning & 2.44 & 42 & 1.58 & 0.87 & 3.70 & 1.09 & 1.70 & 1.09 & 31 \\
\hline spinning & 0.68 & 89 & 2.80 & 1.20 & 2.13 & 0.82 & 3.15 & 1.44 & 31 \\
\hline spraying & 0.74 & 83 & 3.30 & 1.18 & 1.90 & 0.87 & 4.23 & 0.77 & 14 \\
\hline sprinkling & $2.03^{\circ}$ & 64 & 3.28 & 1.20 & 2.58 & 0.81 & 3.10 & 1.50 & 11 \\
\hline squatting & 0.86 & 84 & 2.70 & 1.22 & 1.93 & 0.92 & 4.70 & 0.56 & 12 \\
\hline squeezing & 0.23 & 97 & 3.00 & 1.18 & 1.70 & 0.52 & 3.83 & 1.32 & 30 \\
\hline squinting & 2.10 & 63 & 2.58 & 1.36 & 1.80 & 0.91 & 4.53 & 0.91 & 6 \\
\hline standing & 0.46 & 94 & 3.28 & 1.32 & 1.38 & 0.84 & 4.60 & 1.08 & 468 \\
\hline sticking & 2.28 & 50 & 2.43 & 1.30 & 2.45 & 0.99 & 2.10 & 1.24 & 50 \\
\hline stirring & 0.27 & 95 & 3.88 & 0.94 & 1.80 & 0.65 & 4.13 & 0.82 & 39 \\
\hline straddling & 1.56 & 70 & 1.73 & 0.91 & 2.03 & 0.95 & 3.50 & 1.32 & 5 \\
\hline stretching & 1.25 & 72 & 4.00 & 1.09 & 1.70 & 0.72 & 3.78 & 1.33 & 61 \\
\hline surfing & 0.12 & 98 & 2.30 & 1.52 & 4.00 & 1.11 & 4.95 & 0.22 & 0 \\
\hline sweeping & 0.39 & 94 & 3.70 & 0.91 & 2.00 & 0.68 & 4.68 & 0.76 & 54 \\
\hline swimming & 0.32 & 95 & 3.28 & 1.30 & 3.70 & 1.20 & 4.88 & 0.33 & 55 \\
\hline swinging & 0.00 & 100 & 3.30 & 1.16 & 2.53 & 0.91 & 4.53 & 1.18 & 77 \\
\hline tickling & 0.66 & 91 & 3.73 & 0.99 & 2,90 & 1.08 & 4.70 & 0.69 & 89 \\
\hline tiptoeing & 1.80 & 67 & 2.75 & 1.13 & 1.95 & 0.71 & 4.68 & 0.76 & 2 \\
\hline tracing & 0.92 & 77 & 3.10 & 1.32 & 2.50 & 0.85 & 4.70 & 0.56 & 36 \\
\hline trading & 0.81 & 88 & 2.75 & 1.48 & 2.90 & 1.15 & 4.20 & 1.07 & 47 \\
\hline trimming (cutting) & 2.11 & 19 & 2.48 & 1.18 & 3.60 & 0.96 & $3.95(2.95)$ & $1.10(1.36)$ & 16 \\
\hline tucking & 0.90 & 84 & 4.00 & 0.96 & 2.10 & 0.71 & 3.85 & 1.39 & 9 \\
\hline turning & 0.57 & 91 & 2.05 & 1.26 & 2.78 & 0.77 & 3.58 & 1.41 & 566 \\
\hline twirling & 0.46 & 94 & 2.05 & 1.08 & 2.43 & 0.84 & 3.95 & 1.22 & 6 \\
\hline twisting & 0.55 & 92 & 1.78 & 0.92 & 2.13 & 0.85 & 3.60 & 1.24 & 34 \\
\hline typing & 0.12 & 98 & 4.38 & 0.77 & 2.78 & 0.89 & 4.83 & 0.45 & 12 \\
\hline unlocking & 1.85 & 50 & 4.53 & 0.78 & 2.05 & 0.88 & 4.45 & 0.99 & 18 \\
\hline vacuuming & 0.55 & 92 & 4.00 & 0.88 & 2.13 & 0.76 & 4.80 & 0.41 & 3 \\
\hline walking & 0.32 & 95 & 4.40 & 0.93 & 1.83 & 1.03 & 4.53 & 0.91 & 287 \\
\hline washing & 0.68 & 89 & 4.50 & 0.88 & 2.23 & 0.95 & 3.63 & 1.44 & 83 \\
\hline watching & 0.62 & 91 & 3.90 & 1.17 & 2.10 & 0.98 & 4.18 & 1.20 & 209 \\
\hline watering & 0.79 & 86 & 3.23 & 1.31 & 2.40 & 0.84 & 4.75 & 0.59 & 12 \\
\hline waving & 0.27 & 95 & 3.90 & 1.08 & 1.58 & 0.71 & 4.68 & 0.69 & 30 \\
\hline weaving & 3.41 & 30 & 1.53 & 0.93 & 4.03 & 1.03 & 3.95 & 1.28 & 20 \\
\hline weighting & 0.00 & 100 & 3.60 & 1.22 & 1.88 & 0.79 & 4.78 & 0.48 & 33 \\
\hline whispering & 0.62 & 89 & 3.25 & 1.10 & 2.10 & 0.67 & 4.73 & 0.64 & 31 \\
\hline whittling & 2.51 & 39 & 2.28 & 1.30 & 2.93 & 1.14 & 4.15 & 1.53 & 0 \\
\hline winding & 1.73 & 70 & 2.13 & 1.07 & 2.03 & 0.77 & 2.88 & 1.47 & 29 \\
\hline winking & 0.62 & 91 & 3.03 & 1.12 & 1.88 & 0.91 & 4.88 & 0.33 & 18 \\
\hline wiping & 1.92 & 53 & 3.63 & 1.10 & 1.75 & 0.59 & 3.30 & 1.20 & 35 \\
\hline wrestling & 0.32 & 95 & 2.85 & 1.42 & 4.33 & 1.00 & 4.98 & 0.16 & 3 \\
\hline yawning & 1.01 & 73 & 3.18 & 1.43 & 3.03 & 1.21 & 3.65 & 1.29 & 3 \\
\hline
\end{tabular}


APPENDIX B (Continued)

\begin{tabular}{|c|c|c|c|c|c|c|c|c|c|}
\hline \multirow{2}{*}{$\begin{array}{c}\text { Target Response } \\
\text { (Dominant Response) }\end{array}$} & \multicolumn{2}{|c|}{$\begin{array}{c}\text { Name } \\
\text { Agreement }\end{array}$} & \multicolumn{2}{|c|}{ Familiarity } & \multicolumn{2}{|c|}{$\begin{array}{c}\text { Visual } \\
\text { Complexity }\end{array}$} & \multicolumn{2}{|c|}{ Image Agreement } & \multirow{2}{*}{$\begin{array}{c}\text { Word } \\
\text { Frequency }\end{array}$} \\
\hline & $H$ & $\%$ & $M$ & $S D$ & $M$ & $S D$ & $M$ & $S D$ & \\
\hline yelling & 1.31 & 69 & 3.70 & 1.07 & 1.80 & 0.72 & 4.68 & 0.62 & 31 \\
\hline absorbed & 2.26 & 41 & 3.90 & 1.06 & 2.18 & 0.68 & 4.20 & 1.11 & 41 \\
\hline addressed & 1.05 & 84 & 3.68 & 1.27 & 2.58 & 1.26 & 4.55 & 0.90 & 40 \\
\hline assembled & 2.38 & 52 & 2.25 & 1.17 & 3.43 & 1.15 & 3.75 & 1.21 & 39 \\
\hline baked & 0.74 & 83 & 3.95 & 1.24 & 2.68 & 0.80 & 4.33 & 1.23 & 15 \\
\hline broken & 1.42 & 56 & 3.78 & 1.21 & 2.45 & 1.13 & 4.55 & 0.85 & 228 \\
\hline buried & 2.01 & 48 & 2.68 & 1.25 & 2.88 & 1.22 & 4.28 & 0.91 & 24 \\
\hline carved & 0.12 & 98 & 3.78 & 1.23 & 2.93 & 1.29 & 4.25 & 0.98 & 23 \\
\hline caught & 0.93 & 86 & 3.88 & 0.91 & 1.98 & 0.83 & 4.00 & 1.18 & 146 \\
\hline chewed & 0.23 & 97 & 4.10 & 0.98 & 2.63 & 1.00 & 4.30 & 0.97 & 16 \\
\hline chipped & 0.89 & 83 & 3.05 & 1.24 & 2.20 & 0.94 & 4.25 & 1.10 & 10 \\
\hline chopped & 1.46 & 56 & 3.78 & 1.21 & 2.90 & 1.15 & 4.59 & 1.00 & 9 \\
\hline closed & 0.20 & 97 & 4.58 & 0.71 & 1.48 & 0.64 & 4.00 & 0.93 & 174 \\
\hline coiled & 2.53 & 36 & 2.73 & 1.45 & 2.08 & 0.80 & 4.47 & 0.87 & 2 \\
\hline connected & 2.09 & 64 & 3.15 & 1.53 & 2.70 & 1.07 & 3.43 & 1.32 & 44 \\
\hline cracked & 1.05 & 80 & 3.50 & 1.09 & 2.15 & 0.83 & 3.80 & 1.34 & 41 \\
\hline crumbled & 2.22 & 53 & 3.48 & 1.11 & 1.95 & 0.85 & 3.75 & 1.13 & 7 \\
\hline cut & 2.17 & 44 & 3.50 & 1.11 & 1.60 & 0.71 & 3.85 & 1.31 & 245 \\
\hline developed & 0.81 & 88 & 3.18 & 1.36 & 3.58 & 1.13 & 3.65 & 1.48 & 322 \\
\hline dissolved & 2.03 & 42 & 2.93 & 1.33 & 2.38 & 0.77 & 4.20 & 0.85 & 23 \\
\hline drank & 1.33 & 78 & 4.53 & 0.68 & 2.18 & 0.93 & 4.30 & 0.94 & 93 \\
\hline drawn & 1.52 & 66 & 3.53 & 1.30 & 2.65 & 1.10 & 4.33 & 1.05 & 222 \\
\hline dressed & 0.43 & 94 & 3.33 & 1.44 & 2.70 & 1.02 & 4.45 & 0.88 & 67 \\
\hline dropped & 0.35 & 95 & 3.63 & 1.17 & 1.53 & 0.68 & 4.03 & 1.10 & 159 \\
\hline dug & 1.82 & 72 & 2.83 & 1.34 & 2.80 & 1.02 & 4.28 & 0.93 & 32 \\
\hline emptied & 0.57 & 91 & 3.58 & 1.15 & 2.23 & 0.95 & 4.20 & 1.11 & 12 \\
\hline enlarged & 1.21 & 81 & 2.40 & 1.24 & 2.75 & 1.03 & 4.08 & 1.07 & 17 \\
\hline extinguished & 2.50 & 48 & 4.08 & 1.10 & 1.75 & 0.67 & 4.05 & 1.13 & 2 \\
\hline fell & 1.73 & 56 & 3.75 & 1.06 & 1.93 & 0.76 & 3.70 & 1.32 & 239 \\
\hline filled & 0.23 & 97 & 3.43 & 1.17 & 2.75 & 1.01 & 4.30 & 1.11 & 184 \\
\hline fixed & 1.00 & 78 & 3.20 & 1.34 & 2.45 & 1.13 & 4.03 & 1.12 & 109 \\
\hline framed & 0.00 & 100 & 3.38 & 1.17 & 2.43 & 0.98 & 4.73 & 0.72 & 23 \\
\hline frayed & 3.00 & 47 & 2.90 & 1.19 & 2.15 & 0.98 & 4.33 & 1.10 & 3 \\
\hline fried (cooked) & 1.27 & 44 & 3.90 & 1.10 & 2.60 & 0.93 & $4.03(4.65)$ & $1.05(0.61)$ & 8 \\
\hline frozen & 2.52 & 48 & 2.83 & 1.13 & 2.83 & 1.15 & 3.50 & 1.43 & 53 \\
\hline gave (received) & 2.08 & 8 & 3.70 & 1.11 & 2.15 & 0.83 & $4.00(3.45)$ & $1.12(1.43)$ & 1264 \\
\hline grew & 2.63 & 27 & 3.35 & 1.25 & 2.73 & 1.18 & 4.59 & 0.87 & 300 \\
\hline ground & 2.27 & 53 & 2.85 & 1.23 & 2.90 & 0.98 & 3.88 & 1.49 & 26 \\
\hline ironed & 1.21 & 81 & 3.28 & 1.09 & 2.78 & 1.07 & 4.50 & 0.88 & 8 \\
\hline jumped & 1.12 & 81 & 3.50 & 1.24 & 1.93 & 0.86 & 4.68 & 0.73 & 58 \\
\hline labeled & 1.52 & 75 & 3.33 & 1.27 & 2.05 & 0.85 & 4.35 & 1.03 & 17 \\
\hline lifted & 1.17 & 81 & 4.33 & 0.80 & 2.20 & 0.85 & 4.50 & 0.75 & 69 \\
\hline lit & 1.44 & 70 & 3.70 & 1.26 & 1.85 & 0.74 & 4.60 & 0.93 & 72 \\
\hline lowered & 3.03 & 41 & 3.25 & 1.33 & 1.53 & 0.78 & 2.58 & 1.26 & 32 \\
\hline mixed & 0.85 & 80 & 3.75 & 1.15 & 3.50 & 1.18 & 4.30 & 1.14 & 56 \\
\hline nailed & 1.30 & 77 & 3.38 & 1.23 & 2.28 & 0.91 & 4.45 & 0.93 & 12 \\
\hline peeled & 0.84 & 88 & 3.68 & 1.05 & 2.38 & 0.87 & 4.30 & 1.11 & 14 \\
\hline poked & 1.94 & 64 & 2.83 & 1.39 & 1.83 & 0.68 & 2.95 & 1.38 & 13 \\
\hline popped & 0.46 & 94 & 3.53 & 1.22 & 1.75 & 0.87 & 4.28 & 1.18 & 17 \\
\hline removed & 0.89 & 88 & 4.23 & 0.80 & 1.95 & 0.85 & 3.40 & 1.32 & 146 \\
\hline ripped & 1.46 & 66 & 3.23 & 1.05 & 2.63 & 0.95 & 3.90 & 1.08 & 14 \\
\hline separated & 1.30 & 73 & 3.78 & 1.10 & 2.83 & 0.78 & 3.18 & 1.26 & 67 \\
\hline sharpened & 0.23 & 97 & 4.15 & 0.89 & 1.88 & 0.65 & 4.25 & 1.28 & 7 \\
\hline shredded & 0.55 & 92 & 2.73 & 1.48 & 2.88 & 1.26 & 4.58 & 0.84 & 4 \\
\hline smeared & 1.32 & 67 & 2.68 & 1.16 & 2.28 & 0.99 & 4.10 & 1.01 & 2 \\
\hline snapped & 0.66 & 91 & 3.78 & 1.14 & 2.13 & 0.94 & 2.80 & 1.56 & 38 \\
\hline spit & 1.65 & 70 & 2.65 & 1.29 & 2.33 & 1.07 & 4.13 & 1.04 & 21 \\
\hline spread & 0.50 & 92 & 3.98 & 1.14 & 2.18 & 0.75 & 4.28 & 1.18 & 90 \\
\hline stacked & 0.70 & 89 & 4.30 & 0.82 & 1.78 & 0.58 & 4.53 & 0.99 & 11 \\
\hline stained & 0.86 & 88 & 3.70 & 1.14 & 2.15 & 0.89 & 4.45 & 1.04 & 47 \\
\hline straightened & 2.50 & 56 & 2.78 & 1.19 & 2.10 & 1.15 & 2.63 & 1.39 & 33 \\
\hline switched & 2.05 & 66 & 3.10 & 1.39 & 2.55 & 1.20 & 2.83 & 1.62 & 28 \\
\hline swung & 2.00 & 63 & 3.48 & 1.40 & 2.13 & 0.69 & 3.35 & 1.51 & 77 \\
\hline threaded & 1.33 & 75 & 3.23 & 1.44 & 2.65 & 0.95 & 4.60 & 0.93 & 9 \\
\hline thrown & 1.95 & 42 & 3.93 & 1.02 & 1.98 & 0.80 & 4.38 & 0.95 & 150 \\
\hline tied & 0.50 & 92 & 4.58 & 0.81 & 2.13 & 0.97 & 4.43 & 1.08 & 50 \\
\hline
\end{tabular}


APPENDIX B (Continued)

\begin{tabular}{|c|c|c|c|c|c|c|c|c|c|}
\hline \multirow{2}{*}{$\begin{array}{c}\text { Target Response } \\
\text { (Dominant Response) }\end{array}$} & \multicolumn{2}{|c|}{$\begin{array}{c}\text { Name } \\
\text { Agreement }\end{array}$} & \multicolumn{2}{|c|}{ Familiarity } & \multicolumn{2}{|c|}{$\begin{array}{c}\text { Visual } \\
\text { Complexity } \\
\end{array}$} & \multicolumn{2}{|c|}{ Image Agreement } & \multirow{2}{*}{$\begin{array}{c}\text { Word } \\
\text { Frequency }\end{array}$} \\
\hline & $H$ & $\%$ & $M$ & $S D$ & $M$ & $S D$ & $M$ & $S D$ & \\
\hline toasted & 0.35 & 95 & 4.23 & 0.86 & 2.08 & 0.66 & 4.93 & 0.35 & 9 \\
\hline turned & 0.88 & 86 & 3.85 & 1.29 & 1.70 & 0.76 & 3.13 & 1.34 & 566 \\
\hline wrapped & 0.12 & 98 & 3.83 & 1.08 & 2.88 & 1.02 & 4.65 & 0.92 & 23 \\
\hline wrinkled & 0.77 & 89 & 3.60 & 1.13 & 2.53 & 0.93 & 4.48 & 0.96 & 12 \\
\hline written & 1.64 & 56 & 4.50 & 0.82 & 2.60 & 1.13 & 4.35 & 1.00 & 561 \\
\hline
\end{tabular}

\section{APPENDIX C \\ Effects of Cuing and Prompting on the Percentage of Target Responses Elicited}

Note: Target responses, which represent specific and accurate responses typically produced by $5 \%$ or more of all subjects, were defined for each item. For each item, the percentages of subjects who produced a target response are listed for Experiment 1 (in which no cues or prompts were used) and Experiment 2. For Experiment 2, in some cases the experimenter (1) cued subjects to attend to a particular feature of a picture (indicated in the Cue Used column) by pointing before they produced a response, and/or (2) prompted subjects to produce a second response in cases in which the first response met some criteria. For the cues, the experiment pointed to a person (on the left, L, or right, R), animal, or object and asked, "What is this doing?" or pointed to an object, animal, or part of a person (e.g., the person's hand) and asked, "What is the person doing with (or to) this?" Four different types of prompts were used: (1) "kind of" prompts, to encourage the production of a subordinate response; $(2)$ "single word" prompts, to encourage the production of a single word synonym; (3) "look again" prompts, to encourage the subject to look at important visual details in the stimulus; and (4) "besides" prompts, to encourage the subject to look at a second action depicted in the stimulus. For further details about the prompts, see Experiment 2, Method section. Items are listed in the same order as for Appendix A.

\begin{tabular}{|c|c|c|c|c|c|}
\hline \multirow[b]{3}{*}{ Target Responses } & \multirow{3}{*}{$\begin{array}{c}\text { Experiment } 1 \\
\% \text { Targets }\end{array}$} & \multicolumn{4}{|c|}{ Experiment 2} \\
\hline & & \multicolumn{2}{|c|}{ Ist Response } & \multicolumn{2}{|c|}{ 2nd Response } \\
\hline & & Cue Used & $\%$ Targets & Prompt & $\%$ Targets \\
\hline arranging & 81 & & 80 & & \\
\hline balancing & 95 & & 95 & & \\
\hline bending & 95 & & 100 & & \\
\hline biting & 48 & & 60 & & \\
\hline blocking/stopping & 64 & R person & 83 & & \\
\hline blowing/extinguishing & 100 & & 95 & & \\
\hline blowing/inflating & 100 & & 95 & & \\
\hline bouncing/dribbling & 88 & & 98 & & \\
\hline bowing & 94 & & 95 & & \\
\hline boxing & 94 & & 90 & kind & 93 \\
\hline branding & 44 & w/object & 73 & & \\
\hline brushing & 91 & & 88 & look & 100 \\
\hline bucking & 31 & animal & 75 & kind & 75 \\
\hline canoeing/paddling & 50 & & 55 & kind & 90 \\
\hline carrying & 86 & w/object & 98 & look & 98 \\
\hline chirping/calling & 45 & & 58 & kind & 78 \\
\hline choking/strangling & 95 & & 98 & & \\
\hline clapping & 92 & & 90 & & \\
\hline climbing & 100 & & 100 & & \\
\hline coloring/scribbling & 98 & & 100 & look & 100 \\
\hline conducting/directing & 88 & & 98 & & \\
\hline covering/uncovering & 80 & L person & 83 & & \\
\hline crashing/wrecking & 64 & & 60 & & \\
\hline crawling & 100 & & 100 & & \\
\hline crumpling/wadding & 83 & & 95 & & \\
\hline crushing/smashing & 94 & & 98 & & \\
\hline curling & 97 & & 93 & look & 100 \\
\hline curtsying & 58 & & 53 & look & 70 \\
\hline cutting & 100 & & 100 & & \\
\hline dealing & 88 & & 78 & besides & 78 \\
\hline dialing/calling & 95 & & 100 & & \\
\hline
\end{tabular}


APPENDIX C (Continued)

\begin{tabular}{|c|c|c|c|c|c|}
\hline \multirow[b]{3}{*}{ Target Responses } & \multirow{3}{*}{$\begin{array}{c}\text { Experiment } 1 \\
\% \text { Targets }\end{array}$} & \multicolumn{4}{|c|}{ Experiment 2} \\
\hline & & \multicolumn{2}{|c|}{ 1st Response } & \multicolumn{2}{|c|}{ 2nd Response } \\
\hline & & Cue Used & $\%$ Targets & Prompt & $\%$ Targets \\
\hline directing/signaling & 86 & & 83 & & \\
\hline diving & 89 & & 95 & & \\
\hline diving/swooping & 59 & & 68 & & \\
\hline dragging & 89 & & 85 & kind & 93 \\
\hline dripping & 86 & & 100 & & \\
\hline ducking/dodging/avoiding & 53 & & 60 & & \\
\hline dunking/dipping & 91 & & 98 & & \\
\hline dusting/wiping & 63 & & 70 & kind & 88 \\
\hline eating & 92 & & 93 & & \\
\hline erasing & 98 & & 100 & & \\
\hline erupting & 39 & & 63 & kind & 73 \\
\hline fainting & 77 & $R$ person & 90 & kind & 93 \\
\hline feeding & 81 & $\mathrm{~L}$ person & 100 & & \\
\hline fencing & 72 & & 78 & kind & 78 \\
\hline fighting & 64 & & 80 & besides & 85 \\
\hline fighting/attacking/biting & 84 & & 90 & & \\
\hline fishing & 98 & & 100 & & \\
\hline flexing & 94 & & 98 & single & 100 \\
\hline flipping/tossing & 66 & to object & 65 & & \\
\hline flowing & 53 & object & 78 & & \\
\hline flying & 98 & & 98 & & \\
\hline folding & 95 & & 98 & & \\
\hline following & 17 & $\mathrm{~L}$ animals & 70 & besides & 80 \\
\hline frowning & 31 & w/mouth & 75 & & \\
\hline galloping/trotting & 67 & & 63 & kind & 93 \\
\hline gesturing/motioning & 11 & w/arm & 58 & & \\
\hline grabbing/tugging & 52 & L person & 73 & kind & 80 \\
\hline grating/shredding & 92 & & 98 & & \\
\hline grazing & 63 & & 40 & kind & 83 \\
\hline hammering/nailing/pounding & 100 & & 100 & & \\
\hline hanging & 98 & & 98 & & \\
\hline harvesting/combining/farming & 66 & & 68 & & \\
\hline hatching & 64 & & 83 & kind & 83 \\
\hline herding/rounding (up)/chasing & 33 & to animals & 83 & & \\
\hline hiding & 72 & $\mathrm{~L}$ person & 90 & & \\
\hline hiking/backpacking & 89 & & 95 & & \\
\hline hobbling & 5 & & 0 & kind & 0 \\
\hline holding & 92 & & 98 & & \\
\hline holding & 53 & w/object & 65 & look & 93 \\
\hline hugging/celebrating/rejoicing & 97 & & 85 & & \\
\hline hurdling & 81 & & 95 & kind & 98 \\
\hline interviewing & 28 & $\mathrm{R}$ person & 65 & besides & 78 \\
\hline juggling & 100 & & 100 & & \\
\hline kicking & 97 & & 95 & & \\
\hline kissing & 95 & & 100 & & \\
\hline kneeling & 98 & & 98 & & \\
\hline knitting & 78 & & 80 & & \\
\hline knocking & 92 & & 98 & & \\
\hline laminating & 55 & & 55 & kind & 58 \\
\hline laughing/giggling & 0 & L person & 100 & & \\
\hline leading/guiding & 58 & $\mathrm{R}$ person & 85 & & \\
\hline leaning & 97 & & 100 & & \\
\hline licking/sealing & 98 & & 100 & & \\
\hline lifting/weightlifting & 91 & & 90 & & \\
\hline listening/hearing & 100 & & 95 & & \\
\hline loading/reloading & 88 & & 85 & & \\
\hline looking/searching/peering & 75 & & 100 & besides & 68 \\
\hline mailing/sending & 89 & & 93 & & \\
\hline marching/parading & 95 & & 100 & & \\
\hline measuring & 100 & & 100 & & \\
\hline meditating & 84 & & 88 & kind & 90 \\
\hline melting & 91 & object & 93 & & \\
\hline milking & 97 & & 100 & & \\
\hline mixing/blending/beating & 100 & & 95 & & \\
\hline mounting & 70 & & 53 & single & 63 \\
\hline nursing/sucking/suckling & 31 & $\mathrm{~L}$ animal & 28 & kind & 68 \\
\hline
\end{tabular}


APPENDIX C (Continued)

\begin{tabular}{|c|c|c|c|c|c|}
\hline \multirow[b]{3}{*}{ Target Responses } & \multirow{3}{*}{$\begin{array}{c}\text { Experiment } 1 \\
\% \text { Targets }\end{array}$} & \multicolumn{4}{|c|}{ Experiment 2} \\
\hline & & \multicolumn{2}{|c|}{ 1st Response } & \multicolumn{2}{|c|}{ 2nd Response } \\
\hline & & Cue Used & $\%$ Targets & Prompt & $\%$ Targets \\
\hline offering & 17 & $\mathrm{R}$ person & 65 & kind & 83 \\
\hline opening & 100 & & 100 & & \\
\hline packing/unpacking & 91 & & 70 & & \\
\hline painting & 91 & & 88 & look & 95 \\
\hline parachuting & 72 & & 75 & besides & 78 \\
\hline passing/handing & 58 & & 65 & kind & 78 \\
\hline peeking/hiding/covering & 88 & & 90 & & \\
\hline perching & 31 & & 28 & kind & 50 \\
\hline petting/stroking & 64 & w/hand & 90 & & \\
\hline picking & 94 & & 98 & & \\
\hline pinching & 100 & & 100 & & \\
\hline planting & 61 & to object & 78 & & \\
\hline playing & 95. & & 98 & & \\
\hline plugging & 97 & & 88 & & \\
\hline pointing & 98 & & 100 & & \\
\hline polishing/shining & 91 & & 90 & & \\
\hline pouring & 100 & & 100 & & \\
\hline praying & 97 & & 98 & & \\
\hline pressing/selecting/choosing & 23 & & 33 & kind & 83 \\
\hline pulling & 81 & & 88 & & \\
\hline punching & 91 & & 90 & kind & 100 \\
\hline pushing & 97 & & 98 & & \\
\hline racing & 100 & & 98 & & \\
\hline raking & 100 & & 100 & & \\
\hline reaching & 98 & & 90 & & \\
\hline reading & 98 & & 98 & & \\
\hline rearing & 11 & animal & 20 & kind & 20 \\
\hline receiving/accepting/taking & 6 & $\mathrm{R}$ person & 88 & & \\
\hline refusing/rejecting/denying/ & & & & & \\
\hline $\begin{array}{l}\text { declining } \\
\text { resuscitating/rescuing/ }\end{array}$ & 69 & L person & 95 & single & 98 \\
\hline $\begin{array}{l}\text { resuscitating/rescuing? } \\
\text { reviving/saving }\end{array}$ & 80 & & 80 & kind & 88 \\
\hline riding & 89 & person & 100 & & \\
\hline ringing & 97 & & 98 & & \\
\hline rolling & 91 & & 93 & & \\
\hline roping/lassoing/catching & 80 & to animal & 88 & & \\
\hline rowing & 98 & & 98 & & \\
\hline rubbing/moisturizing/spreading & 63 & & 78 & & \\
\hline running/jogging & 98 & & 98 & & \\
\hline sailing & 95 & & 100 & kind & 100 \\
\hline saluting & 94 & & 90 & & \\
\hline sawing & 97 & & 93 & kind & 98 \\
\hline scratching/itching & 100 & & 100 & & \\
\hline screwing & 89 & w/object & 93 & & \\
\hline scrubbing & 86 & & 83 & kind & 85 \\
\hline $\begin{array}{l}\text { sewing/mending/darning/ } \\
\text { stitching }\end{array}$ & 92 & & 98 & & \\
\hline shaking & 84 & & 75 & besides & 90 \\
\hline sharing & 41 & & 48 & besides & 75 \\
\hline shearing & 61 & & 43 & kind & 48 \\
\hline shooting/hunting & 88 & & 100 & & \\
\hline shoving & 19 & & 30 & kind & 93 \\
\hline shrugging & 33 & w/shoulders & 80 & & \\
\hline shuffling & 97 & & 100 & & \\
\hline signing & 70 & & 85 & kind & 88 \\
\hline singing & 98 & & 98 & & \\
\hline sitting & 9] & & 78 & & \\
\hline skating/ice-skating & 98 & & 98 & & \\
\hline skiing & 100 & & 100 & & \\
\hline slapping/smacking & 95 & & 100 & kind & 100 \\
\hline sledding & 86 & & 88 & besides & 93 \\
\hline sleeping/napping & 97 & & 98 & & \\
\hline slicing & 33 & & 63 & kind & 85 \\
\hline sliding & 100 & & 100 & & \\
\hline sliding & 64 & & 80 & kind & 88 \\
\hline slouching/relaxing/lounging & 45 & & 53 & kind & 70 \\
\hline
\end{tabular}


APPENDIX C (Continued)

\begin{tabular}{|c|c|c|c|c|c|}
\hline \multirow[b]{3}{*}{ Target Responses } & \multirow{3}{*}{$\begin{array}{c}\text { Experiment } 1 \\
\% \text { Targets }\end{array}$} & \multicolumn{4}{|c|}{ Experiment 2} \\
\hline & & \multicolumn{2}{|c|}{ 1st Response } & \multicolumn{2}{|c|}{ 2nd Response } \\
\hline & & Cue Used & $\%$ Targets & Prompt & $\%$ Targets \\
\hline smelling & 97 & & 95 & & \\
\hline smiling & 100 & & 100 & & \\
\hline smoking & 94 & & 95 & & \\
\hline sneezing & 89 & & 95 & & \\
\hline speaking/lecturing/teaching & 75 & & 90 & kind & 90 \\
\hline spilling/leaking/spilled & 94 & & 88 & & \\
\hline spilling/spilled & 94 & & 95 & & \\
\hline spinning & 42 & & 35 & & \\
\hline spinning & 89 & & 100 & besides & 100 \\
\hline spraying/squirting & 98 & & 100 & & \\
\hline sprinkling & 64 & & 70 & & \\
\hline squatting/crouching & 92 & & 95 & & \\
\hline squeezing & 97 & & 98 & & \\
\hline squinting/glaring & 72 & w/eyes & 90 & & \\
\hline standing & 94 & & 100 & & \\
\hline sticking/clinging & 75 & object & 93 & & \\
\hline stirring & 95 & & 95 & & \\
\hline straddling & 70 & & 65 & kind & 70 \\
\hline stretching & 72 & & 94 & look & 94 \\
\hline surfing & 98 & & 95 & & \\
\hline sweeping & 94 & & 83 & & \\
\hline swimming & 95 & & 95 & & \\
\hline swinging & 100 & & 95 & & \\
\hline tickling & 91 & $\mathrm{R}$ person & 100 & & \\
\hline tiptoeing/sneaking/dancing & 84 & & 75 & & \\
\hline tracing & 77 & & 53 & look & 88 \\
\hline trading & 88 & & 90 & look & 90 \\
\hline trimming/pruning & 28 & & 13 & kind & 40 \\
\hline tucking & 84 & & 90 & & \\
\hline turning & 91 & & 83 & & \\
\hline twirling & 94 & & 95 & & \\
\hline twisting/wringing & 95 & & 100 & & \\
\hline typing & 98 & & 95 & & \\
\hline unlocking/locking & 80 & & 83 & kind & 85 \\
\hline vacuuming & 92 & & 98 & & \\
\hline walking/strolling & 98 & & 88 & & \\
\hline washing/rinsing & 95 & & 100 & & \\
\hline watching & 91 & & 90 & & \\
\hline watering & 86 & to object & 88 & & \\
\hline waving & 95 & & 95 & & \\
\hline weaving & 30 & & 15 & & \\
\hline weighing & 100 & & 95 & & \\
\hline whispering & 89 & & 98 & kind & 100 \\
\hline whittling & 39 & & 40 & kind & 58 \\
\hline winding & 70 & & 68 & kind & 75 \\
\hline winking & 91 & & 90 & & \\
\hline wiping & 53 & w/object & 93 & & \\
\hline wrestling & 95 & & 95 & & \\
\hline yawning & 73 & & 90 & besides & 95 \\
\hline yelling/shouting/hollering & 95 & & 98 & & \\
\hline absorbed/soaked & 67 & w/object & 75 & & \\
\hline addressed & 84 & & 83 & & \\
\hline assembled & 52 & & 60 & single & 65 \\
\hline baked & 83 & & 93 & kind & 98 \\
\hline broken/broke/shattered & 100 & & 95 & & \\
\hline buried & 48 & to object & 55 & kind & 65 \\
\hline carved & 98 & & 90 & & \\
\hline caught & 86 & & 88 & & \\
\hline chewed & 97 & & 93 & & \\
\hline chipped & 83 & & 88 & kind & 88 \\
\hline chopped/diced & 86 & & 85 & kind & 88 \\
\hline closed/shut & 100 & & 100 & & \\
\hline coiled/rolled/wound & 73 & & 68 & & \\
\hline connected/joined/attached & 78 & & 63 & & \\
\hline cracked & 80 & & 58 & kind & 95 \\
\hline crumbled & 53 & & 45 & kind & 55 \\
\hline
\end{tabular}


APPENDIX C (Continued)

\begin{tabular}{|c|c|c|c|c|c|}
\hline \multirow[b]{3}{*}{ Target Responses } & \multirow{3}{*}{$\begin{array}{c}\text { Experiment } 1 \\
\% \text { Targets }\end{array}$} & \multicolumn{4}{|c|}{ Experiment 2} \\
\hline & & \multicolumn{2}{|c|}{ Ist Response } & \multicolumn{2}{|c|}{ 2nd Response } \\
\hline & & Cue Used & $\%$ Targets & Prompt & $\%$ Targets \\
\hline cut & 44 & & 40 & look & 65 \\
\hline developed & 88 & & 78 & & \\
\hline dissolved & 42 & to object & 38 & look & 55 \\
\hline drank/emptied & 78 & & 85 & & \\
\hline drawn/drew & 88 & & 98 & & \\
\hline dressed/clothed & 97 & & 100 & & \\
\hline dropped & 95 & & 98 & & \\
\hline dug & 72 & & 80 & & \\
\hline emptied & 91 & & 95 & & \\
\hline enlarged & 81 & & 88 & single & 88 \\
\hline extinguished & 48 & & 50 & single & 55 \\
\hline fell/fallen/dropped & 92 & & 85 & & \\
\hline filled & 97 & & 98 & & \\
\hline fixed/repaired & 95 & & 93 & & \\
\hline framed & 100 & & 98 & & \\
\hline frayed/unraveled & 52 & & 70 & & \\
\hline fried & 44 & & 73 & kind & 95 \\
\hline frozen/froze & 69 & to object & 83 & & \\
\hline gave/given & 25 & $\mathrm{R}$ person & 53 & & \\
\hline grew/grown/sprouted & 61 & objects & 95 & & \\
\hline ground & 53 & & 58 & kind & 63 \\
\hline ironed/pressed & 88 & & 98 & & \\
\hline jumped & 81 & & 78 & & \\
\hline labeled/named/filed & 88 & & 83 & & \\
\hline lifted & 81 & & 73 & single & 78 \\
\hline lit/lighted & 86 & & 88 & & \\
\hline lowered/dropped & 48 & w/arm & 70 & single & 73 \\
\hline $\operatorname{mixed} /$ combined & 97 & & 98 & & \\
\hline nailed/hammered/pounded & 92 & & 90 & & \\
\hline peeled & 88 & & 88 & & \\
\hline poked/punctured/punched & 84 & & 73 & single & 73 \\
\hline popped/burst & 95 & & 93 & & \\
\hline removed & 88 & & 83 & single & 88 \\
\hline ripped/torn/tore & 92 & & 93 & & \\
\hline separated/sorted & 91 & & 85 & & \\
\hline sharpened & 97 & & 100 & & \\
\hline shredded & 92 & & 90 & & \\
\hline smeared/smudged & 92 & & 95 & & \\
\hline snapped & 91 & & 90 & & \\
\hline spit/spat & 75 & & 90 & & \\
\hline spread & 92 & & 95 & & \\
\hline stacked/piled & 94 & & 100 & & \\
\hline stained & 88 & to object & 95 & & \\
\hline straightened/evened & 61 & & 55 & & \\
\hline switched/reversed/rearranged & 80 & & 80 & & \\
\hline swung & 63 & to object & 73 & & \\
\hline threaded & 75 & & 75 & & \\
\hline thrown/threw/tossed & 92 & & 75 & & \\
\hline tied & 92 & & 88 & & \\
\hline toasted & 95 & & 88 & & \\
\hline turned & 86 & & 88 & & \\
\hline wrapped & 98 & & 100 & & \\
\hline wrinkled & 89 & & 98 & & \\
\hline written/wrote & 88 & & 98 & & \\
\hline
\end{tabular}

(Manuscript received November 3, 1995;

revision accepted for publication April 30, 1996.) 